\title{
The effects of mental practice in neurological rehabilitation; a systematic review and meta-analysis
}

\author{
Susy Braun ${ }^{1,2 *}$, Melanie Kleynen ${ }^{1,3}$, Tessa van Heel ${ }^{4}$, Nena Kruithof ${ }^{4}$, Derick Wade ${ }^{5}$ and \\ Anna Beurskens ${ }^{1,2}$ \\ ${ }^{1}$ Research Centre Autonomy and Participation of Patients with a Chronic Illness, Zuyd University of Applied Sciences, Heerlen, Netherlands \\ 2 School for Public Health and Primary Care (CAPHRI), Maastricht University, Maastricht, Netherlands \\ ${ }^{3}$ Adelante Centre of Expertise in Rehabilitation and Audiology, Hoensbroek, Netherlands \\ ${ }^{4}$ Department for Health and Technique, Physiotherapy, Zuyd University of Applied Sciences, Heerlen, Netherlands \\ ${ }^{5}$ Oxford Centre for Enablement, Oxford, UK
}

\section{Edited by:}

Magdalena letswaart, Northumbria University, UK

Reviewed by:

Nikhil Sharma, National Institutes of Health, USA

Francine Malouin, Laval University and CIRRIS, Canada

Frederike M. Van Wijck, Glasgow

Caledonian University, UK

*Correspondence:

Susy Braun, Research Centre

Autonomy and Participation of

Patients with a Chronic IIIness, Zuyd

University of Applied Sciences,

Nieuw Eyckholt 300, 6419 DJ

Heerlen, P.O. Box 550, 6400 AN,

Heerlen, Netherlands

e-mail: susy.braun@zuyd.nl
Objective: To investigate the beneficial and adverse effects of a mental practice intervention on activities, cognition, and emotion in patients after stroke, patients with Parkinson's disease or multiple sclerosis.

Methods: Electronic databases PubMed/Medline, PEDro, Science Direct, Cochrane Library, PsycINFO, Rehadat, Embase, and Picarta were searched until June 2012. Fourteen randomized controlled trials in stroke and two randomized controlled trials in Parkinson's disease were included, representing 491 patients (421 with stroke). No randomized controlled trials in multiple sclerosis were identified. The methodologic quality of the included trials was assessed with the Amsterdam-Maastricht-Consensus-List (AMCL). Information on study characteristics and outcomes was summarized and evidence for effects described. Data from individual studies in stroke with same outcome measures were pooled.

Results: The included 16 randomized controlled trials were heterogeneous and methodologic quality varied. Ten trials reported significant effects in favor of mental practice in patients with stroke $(n=9)$ and Parkinson's disease $(n=1)$. In six studies mental practice had similar effects as therapy as usual $(n=5$ in stroke and $n=1$ in Parkinson's disease). Of six performed meta-analyses with identical measures in stroke studies only two showed significant effects of mental practice: short-term improvement of arm-hand-ability (ARAT: SMD 0.62; 95\% Cl: 0.05 to 1.19) and improvement of performance of activities (NRS: SMD 0.9; 95\% Cl: 0.04 to 1.77). Five studies found effects on cognition (e.g., effects on attention, plan actions in unfamiliar surroundings) and four reported observed side-effects, both positive (e.g., might increase motivation and arousal and reduce depression) and negative (e.g., diminished concentration, irritation).

Conclusions: Mental practice might have positive effects on performance of activities in patients with neurological diseases, but this review reports less positive results than earlier published ones. Strengths and limitations of past studies are pointed out. Methodologic recommendations for future studies are given.

Keywords: neurorehabilitation, mental practice, systematic review, meta-analysis

\section{INTRODUCTION}

Neurological pathologies affect many patients profoundly, causing loss of activities, which often leads to intensive rehabilitation periods (Munneke et al., 2010; Keus et al., 2012). Three often researched neurological conditions of the upper motor neuron are stroke, Parkinson's disease, and multiple sclerosis. The complexity and intensity of neurological multidisciplinary rehabilitation leads to high costs, which will increase as the numbers of patients with a neurological disorder rise (Evers et al., 2004; Struijs et al., 2005; Findley, 2007).

While it is reasonably established that the overall process of neurological rehabilitation is effective, there is little evidence to support many specific rehabilitation therapeutic techniques (Keus et al., 2007a; Langhorne et al., 2009). Currently task orientated practice (i.e., practising a meaningful activity within the context of relevance) and intensity are considered the basis for effective therapeutic techniques (Trombly and Wu, 1999; Langhorne et al., 2009).

Mental practice of tasks is a relatively new therapy that is receiving a lot of attention within rehabilitation research (de Vries and Mulder, 2007; Langhorne et al., 2009). Mental practice can be defined as: "The repetition or rehearsing of imagined motor acts with the intention of improving their physical execution" (Malouin and Richards, 2010). Practicing a skill mentally 
is a potential method to increase the amount of practice during rehabilitation in a safe way with relatively low costs. After initial learning, the mental practice technique can be practiced by the patient independent from the therapist, location, and time of the day.

Over the last decade, many articles investigating the effects of mental practice have been published, including five systematic reviews (Braun et al., 2006; Zimmermann-Schlatter et al., 2008; Nilsen et al., 2010; Barclay-Goddard et al., 2011; Cha et al., 2012). Within neurological rehabilitation, the reviews are restricted to evidence of mental practice in stroke populations. Four reviews focused on upper limb abilities (Zimmermann-Schlatter et al., 2008; Nilsen et al., 2010; Barclay-Goddard et al., 2011; Cha et al., 2012). All reviews included a relatively small number of randomized or clinically controlled trials [four (ZimmermannSchlatter et al., 2008), five (Braun et al., 2006; Cha et al., 2012), or six (Nilsen et al., 2010; Barclay-Goddard et al., 2011) trials]. The total number of participants on which the evidence was based within the separate reviews ranged from 86 (ZimmermannSchlatter et al., 2008) to 146 (Cha et al., 2012). All systematic reviews conclude that mental practice might be a potential tool to improve motor functions and activities, but that no definite conclusions on the effects of mental practice can be drawn yet, because the evidence base is relatively small. In addition, the reviews recommend that future research should include identification of who will probably benefit most from mental practice, incorporate follow up measuring points (retention) and investigate whether there are differences in effects of the kind of imagery used (e.g., kinesthetic vs. visual imagery and first vs. third person's view).

Despite the number of recent reviews, there is a need for constant updates of evidence because of the increasing numbers of publications and developments made in this specific area of expertise. Barclay-Goddard et al. (2011) described on-going trials in their Cochrane review in 2011 and estimated that with those studies included the population size on which the evidence would be based would triple (well over 400 participants included). Indeed new studies including some with relatively large sample sizes have been published recently (Ietswaart et al., 2011; Welfringer et al., 2011; Braun et al., 2012; Schuster et al., 2012) and have not yet been included in a review.

Studies assessing the potential of mental practice up until now focused mainly on physical effects. Nilsen et al. (2010) concluded in their review that the variety of effects should be reported more extensively and investigated in future research and Barclay-Goddard et al. emphasize that side-effects, compliance, and integrity should be monitored more closely and reported in future studies (Barclay-Goddard et al., 2011). Mental practice has been shown to regulate arousal, increase control of emotions and improve self-awareness and self-confidence in athletes (Murphy and Jowdy, 1992; Martin et al., 1999) and increase quality of life in patients with breast-cancer (Freeman et al., 2008). At the same time mental imagery may lead to negative side-effects in some patients with complex regional pain syndrome: pain and swelling increased after mental practice use (Moseley et al., 2008).

Although the evidence is yet inconclusive mental practice is recommended to improve arm-hand-abilities in stroke guidelines
(Royal College of Physicians of London, 2008; Australian Stroke Foundation, 2010).

Besides in stroke, mental practice has been used in patients with Parkinson's disease and multiple sclerosis. Although it is not possible to compare these target populations in terms of pathology, symptoms, and recovery pattern, the clinical approach for all three patient groups share considerable similarities (e.g., the mental practice instructions given in clinical practice). Within rehabilitation all groups need intensive, task relevant practice. The underlying hypothesis for the value of mental practice is the same: (1) activation of brain regions related to motor function (Johnson, 2000; Cunnington et al., 2001) and (2) increase of intensity of practice without the need to take issues related to safety and physical fatigue into account (Keus et al., 2007b; van Peppen et al., 2007).

The effects of mental practice in Parkinson's disease and multiple sclerosis have not been taken into account in earlier reviews.

The main objective of this study was to undertake a systematic review and a meta-analysis of randomized controlled trials investigating the beneficial and adverse effects of a mental practice intervention on activities, cognition, and emotion in patients after stroke, patients with Parkinson's disease or patients with multiple sclerosis.

Strengths and limitations of past studies will be pointed out in order to give recommendations in the discussion section on the content and organization of future trials (Craig et al., 2008).

\section{METHODS}

An overview of the search strategy, selection criteria, quality assessment, and meta-analysis is given in Figure $\mathbf{1}$.

\section{DATA SOURCES}

Computer-aided search was performed by four researchers (Susy Braun, Melanie Kleynen, Tessa van Heel, Nena Kruithof) using PubMed/Medline, PEDro, Science Direct, Cochrane Library, PsycINFO, Rehadat, Embase, and Picarta. The authors handsearched reference lists of obtained articles (reference and author tracking). Key words used were: stroke, Parkinson's disease, multiple sclerosis, mental practice, movement and motor imagery, motor learning, rehabilitation, physical therapy, occupational therapy, activities of daily living. These search terms were used in Dutch and German articles as well and were translated if necessary. The detailed search strategy is available from the authors.

\section{STUDY SELECTION \\ Type of study}

The studies selected in the review were all available randomized controlled trials in English, German, and Dutch up to June 2012 that reported the effects of mental practice on the improvement of activities during the rehabilitation of adult participants after stroke, with Parkinson's disease or multiple sclerosis. In cross-over trials, only the first phase of the study was taken into account. A study with mixed population was only selected if the majority (over $50 \%$ ) of participants had been diagnosed with stroke, Parkinson's disease, or multiple sclerosis. 


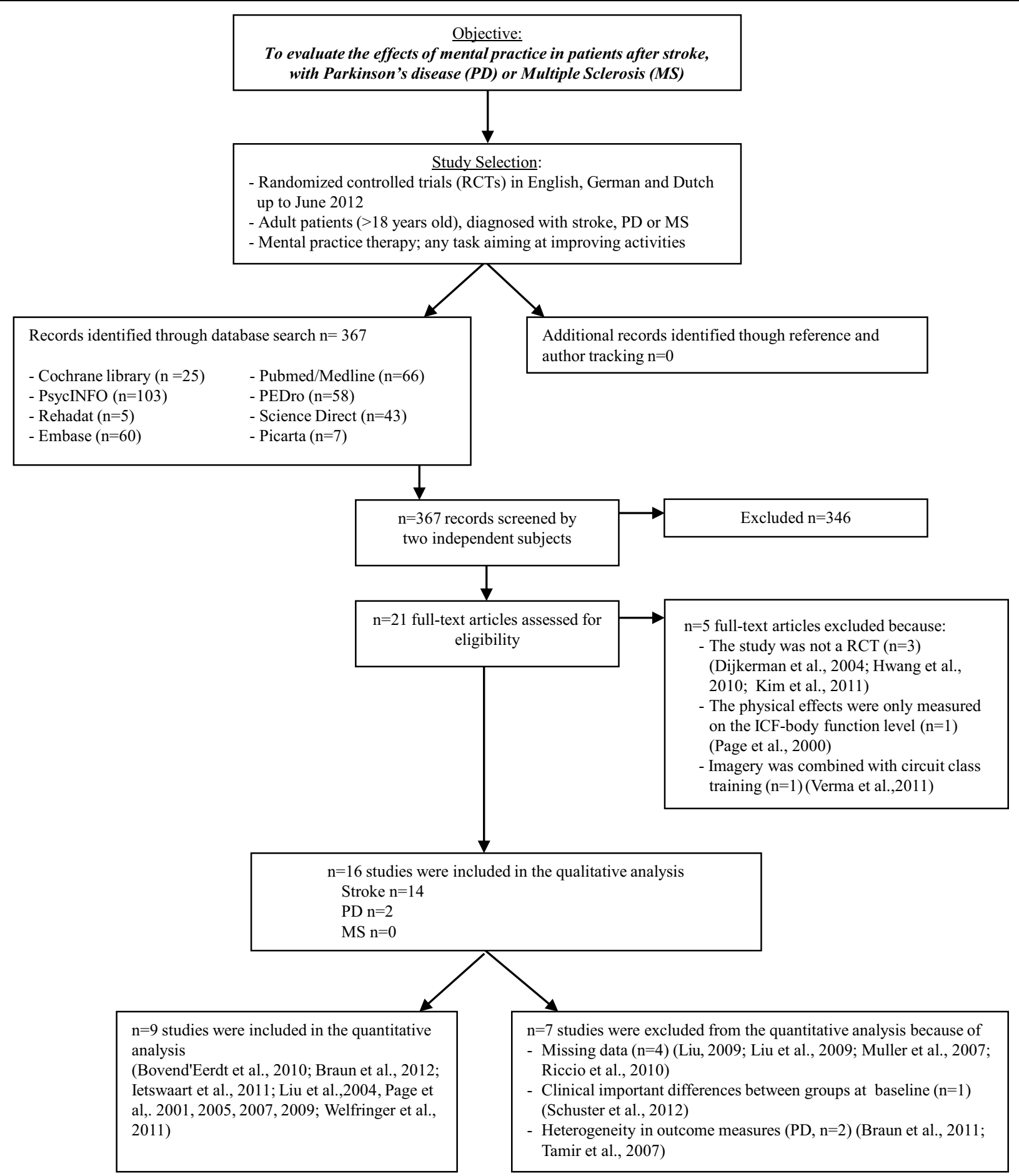

FIGURE 1 | Overview of literature search. Abbreviations: MP, mental practice; PD, Parkinson's disease; MS, multiple sclerosis; RCTs, randomized controlled trials.

\section{Type of intervention}

The mental practice intervention could be added to therapy (e.g., using a taped instruction), embedded in therapy (e.g., problemsolving strategies in which overt movements are combined with mental practice during physical or occupational therapy) or given as an independent intervention. Studies in which special equipment was required (such as electro-myographic stimulation and feedback or forms of virtual reality with computer simulation) were excluded. The content of the control intervention should allow the assessment of possible effects of a mental practice intervention. 


\section{Type of outcome}

Outcome measures can be divided into categories according to the international classification of the World Health Organization (ICF; WHO, 2013) of "function" (e.g., a function could be "pain" measured with a "numeric rating scale"), "activity" (e.g., an activity could be "standing up from a chair" measured with a "timed up and go") and "participation" (e.g., participation could be "providing meals" or "performing (paid) work"). For patients it is important that interventions reduce activity limitations to enable participation in society after returning home. Randomized controlled trials were selected if at least one measure was used for assessing physical effects on the activity level.

\section{DATA EXTRACTION AND QUALITY ASSESSMENT}

Screening on tittle and abstract was performed by two researchers (Susy Braun, Melanie Kleynen) independently. If based on the information in the abstract, it was not clear whether the study should be included the full-text of the article was assessed.

Methodologic quality assessment of the studies was assessed using the Amsterdam-Maastricht Consensus List for Quality Assessment (AMCL; Van Tulder et al., 2003). The AMCL was originally developed by van Tulder et al. for the Cochrane Collaboration Back Group and includes all criteria of other prominent quality scales like the Delphi List (Verhagen et al., 1998). It rates a study's internal validity and statistical reporting using an 11-point scale (12 criteria), with higher scores indicating higher quality. Each criterion was scored either positive (,+ 1 point), negative (,- 0 points), or unclear (?, 0 points), leading to a maximum score of 11 points per study (1 point for the items $2-11 ; 1 / 2$ point for the items $1 \mathrm{a}$ and $1 \mathrm{~b})$.

To increase uniformity in the assessment the validity criteria were defined and then discussed by the two researchers (Susy Braun, Melanie Kleynen). Each item of the AMCL was explained in a separate document that provided uniform operationalization of criteria. In the Appendix the definitions and cut-offs of the criteria of the AMCL are described (Table A1). For example "an acceptable percentage of withdrawals" (criterion 7) was defined as: $10 \%$ during the intervention period and from the remaining sample $10 \%$ during follow-up as suggested by Van Tulder et al. (2003) Compliance (criterion 5) was considered acceptable if participants themselves or therapists and relatives reported that the participants followed the given instructions. A follow-up period (criterion 10) of at least 3 months was considered clinically relevant for this type of intervention. For these last two mentioned criteria (criteria 5 and 10) reviews of other interventions within health care were used as standard, for generally accepted references in literature were not found (Huibers et al., 2003; Van Tulder et al., 2003). If disagreement on the scores persisted, a third researcher (Anna Beurskens) was approached to reach consensus. A study was defined as being of "sufficient quality" if the score was equal to or above six points. As standard references from the literature are missing, the cut-off was defined by the authors after references from other reviews in physical therapy were taken into account (van Tulder et al., 2001; Van Tulder et al., 2003; Huibers et al., 2003).
Authors of the included articles were contacted to clarify the items on which a question mark was scored. Both scores (blinded assessment as well as after contact with authors) are presented.

Information was extracted from each included trial on: (1) study and population (including number of participants and mean age); (2) type of intervention. We for instance wanted to know if an instruction period for therapists and participants was embedded within the mental practice intervention period (e.g., stepwise approach, tools to check compliance) and what the content of the mental imagery session would be (e.g., what activities were rehearsed and how the imagery was instructed e.g., tape, therapist.); (3) type of outcome measure for physical recovery (primary and secondary measurements, assessment time points, and follow-up period); (4) conclusion (is mental practice recommended and what are the (significant) effects on physical recovery). The conclusions were based on the results and conclusions in the articles but summarized by the independent researchers; (5) All included articles were screened on possibly reported effects on cognition or emotion as well as side-effects (quantitative and qualitative measures). If (secondary) measures were used to consciously search and systematically identify effects on cognition or emotion within the study design the results were categorized as "effects." Side-effects are described as effects that were not intended, but were observed and reported. These side-effects could be therapeutic (positive) or adverse (negative). Both independent reviewers extracted data from the full papers by using a pre-structured standard form.

\section{DATA SYNTHESIS OF THE META-ANALYSIS}

A meta-analysis was conducted using Review Manager version 5.1.6. (The Nordic Cochrane Centre TCC, 2011). Post intervention scores and if possible follow-up scores (at least 3 months) were used. Short- and long-term effects of the intervention were distinguished for two reasons: initial effects might extinguish over time and most studies did not perform a follow-up. Data from both measuring moments were analysed separately. Studies were excluded from the analyses if not all necessary data was provided in the article. No data was imputed.

If a study included two control groups, mental practice was compared to the group with the least chance of improvement (e.g., control group). If no significant differences were found between those groups, it was assumed that no differences would be found between the two experimental groups.

Studies with identical physical effect measurement instruments or studies with instruments measuring the same construct were pooled. The Mean Difference (MD) and 95\% confidence interval (95\% CI) was used if data was based on identical measurement instruments and the Standardized Mean Difference (SMD) for data based on different measurement instrument. Statistical heterogeneity was assessed using the $\mathrm{I}^{2}$-statistic. If $\mathrm{I}^{2}$ was greater than $50 \%$ outcomes were pooled using SMD with a random effects model. If there was a big variance in Standard Deviations (SD) across studies, reflecting differences in the real variability of outcomes, we also used the SMD. Sensitivity analysis was done to investigate the influence of studies with ACML scores below 6 (lower quality studies). If for instance data were 
pooled from studies with both lower and high quality, the analysis was performed first with all studies and then repeated without the lower quality studies (Barclay-Goddard et al., 2011).

\section{RESULTS}

In total 367 articles were identified in Pubmed/Medline $(n=66)$, PEDro $(n=58)$, Science Direct $(n=43)$, Cochrane Library $(n=$ $25)$, PsychINFO $(n=103)$, Rehadat $(n=5)$, Embase $(n=60)$, and Picarta $(n=7)$ and 346 were rejected based on title and abstract due to the following reasons: (1) the study was not a randomized controlled trial; (2) the study population did not meet the inclusion criteria; (3) the use of mental practice considered specific equipment; (4) physical effects were only measured on the ICF-body function level; (5) a combination of the reasons above. Of the 21 remaining studies another five articles were excluded after reading the document full-text: one of the studies investigated the effects of mental practice only on the ICF-body function level (only the Fugl Meyer Assessment was used as outcome measure; Page, 2000), three studies were not a randomized controlled trial (Dijkerman et al., 2004; Hwang et al., 2010; Kim et al., 2011), and the last article which was excluded compared imagery combined with circuit class training with Bobath. As the control study did not involve circuit class training, it was unclear what the surplus of the imagery training would be (Verma et al., 2011). Furthermore, the effectiveness and efficiency of circuit training has been established in earlier research (van de Port et al., 2012).

No new articles were retrieved by using reference- and author tracking, leading to a total of sixteen included studies of which 14 in stroke patients and two in patients with Parkinson's disease. No randomized controlled trials with patients with multiple sclerosis were found. In total, 491 participants were included in this systematic review; 421 participants after stroke and 70 participants with Parkinson's disease. The total number of participants in a single study varied from 10 (Page, 2000) to 121 participants (Ietswaart et al., 2011). Group sizes for the experimental intervention varied from 5 to 39 and for the control intervention from 5 to 32 (Page et al., 2009; Ietswaart et al., 2011).

\section{EFFECTS PHYSICAL OUTCOME AND METHODOLOGIC QUALITY}

The scores on the AMCL (range 0-11 points) of the included studies varied from 3.5 to 8 points after blinded assessment of the reviewers. After additional information was retrieved through authors contact (directly or through earlier confirmed information by the authors in the Cochrane review (Barclay-Goddard et al., 2011)) to clarify the questions marks the scores ranged from 6 to 9 points (Table 1 ).

Based on the scores after assessment of the articles by the independent reviewers of the text only, 11 of the 16 studies scored 6 points or more and were considered to have sufficient methodologic quality (Page et al., 2001, 2005, 2009; Liu et al., 2004; Tamir et al., 2007; Liu, 2009; Bovend'Eerdt et al., 2010; Braun et al., 2011a, 2012; Ietswaart et al., 2011; Welfringer et al., 2011). After additional information was processed three more studies came to a total score above six points (Page et al., 2007; Riccio et al., 2010; Schuster et al., 2012). Of these 14 studies with at least sufficient quality, half $(n=7)$ showed overall positive effects of mental practice on arm-hand-function, activities of daily living and mobility of which six in stroke (Page et al., 2001, 2005, 2007, 2009; Liu et al., 2004; Riccio et al., 2010) and one in Parkinson's disease (Tamir et al., 2007). In three high quality studies in stroke positive results were found in favor of the experimental group but not on all outcome measures (Liu, 2009; Welfringer et al., 2011; Schuster et al., 2012) and four high quality studies reported similar effects in the control and experimental group, of which three in stroke (Bovend'Eerdt et al., 2010; Ietswaart et al., 2011; Braun et al., 2012) and one in Parkinson's disease (Braun et al., 2011a). Of the two remaining low quality studies in stroke, one study did not find significant differences between groups (Muller et al., 2007) and one study had mixed results (Liu et al., 2009).

\section{EFFECTS ON PHYSICAL OUTCOMES IN RELATION TO PATIENT CHARACTERISTICS}

Study characteristics of the included randomized controlled trials are shown in Table 2.

Age of the participants varied from 40 to 84 years. The time post-stroke differed greatly, ranging from 0 to 7 days after stroke (Liu et al., 2009) to the chronic phase of recovery (>6 months after stroke; Page et al., 2007; Schuster et al., 2012). The average time after the diagnosis of participants with Parkinson's disease was between 5.2 and 7.8 years. Based on these qualitative descriptions mental practice seems to have potential effects in all ages of participants and phases of stroke recovery. In participants with Parkinson's disease, effects of mental practice were more often reported in the two included studies in participants with Hoehn and Yahr stage 1 or 2 .

\section{EFFECTS ON PHYSICAL OUTCOMES IN RELATION TO INTERVENTION CHARACTERISTICS}

Six studies embedded mental practice in therapy (Liu et al., 2004, 2009; Tamir et al., 2007; Bovend'Eerdt et al., 2010; Braun et al., 2011a, 2012), nine studies added mental practice to therapy (Page et al., 2001, 2005, 2007, 2009; Muller et al., 2007; Liu, 2009; Riccio et al., 2010; Ietswaart et al., 2011; Welfringer et al., 2011) and one study investigated both embedded and added mental practice (Schuster et al., 2012).

The intervention in the control group varied from a single intervention like relaxation therapy (Page et al., 2005, 2007), (general) information (Page et al., 2001), embedded therapy as usual (Muller et al., 2007; Tamir et al., 2007; Page et al., 2009; Bovend'Eerdt et al., 2010; Riccio et al., 2010; Braun et al., 2011a, 2012; Ietswaart et al., 2011; Welfringer et al., 2011; Schuster et al., 2012) to therapy according to the demonstration-then-practice method (Liu, 2009; Liu et al., 2004, 2009).

The activities or skills practiced in the intervention group could be restricted to only movements of the arm (e.g., drinking from a cup; Page et al., 2005) or could contain complex tasks involving the entire body (e.g., going to the park; Liu et al., 2009). Frequency of the intervention varied from two to five times a week, while the intervention lasted between 30 and 60 min per session and continued for 2 to 10 weeks. The included studies used different types of imaging (Mulder, 2007): participants were offered kinesthetic motor imagery (Page et al., 2005; Riccio et al., 2010; Ietswaart et al., 2011; Welfringer et al., 2011), or a combination of kinesthetic and visual motor imagery (Page et al., 2001, 2007, 2009; Liu et al., 2004, 2009; Muller et al., 2007; Tamir 


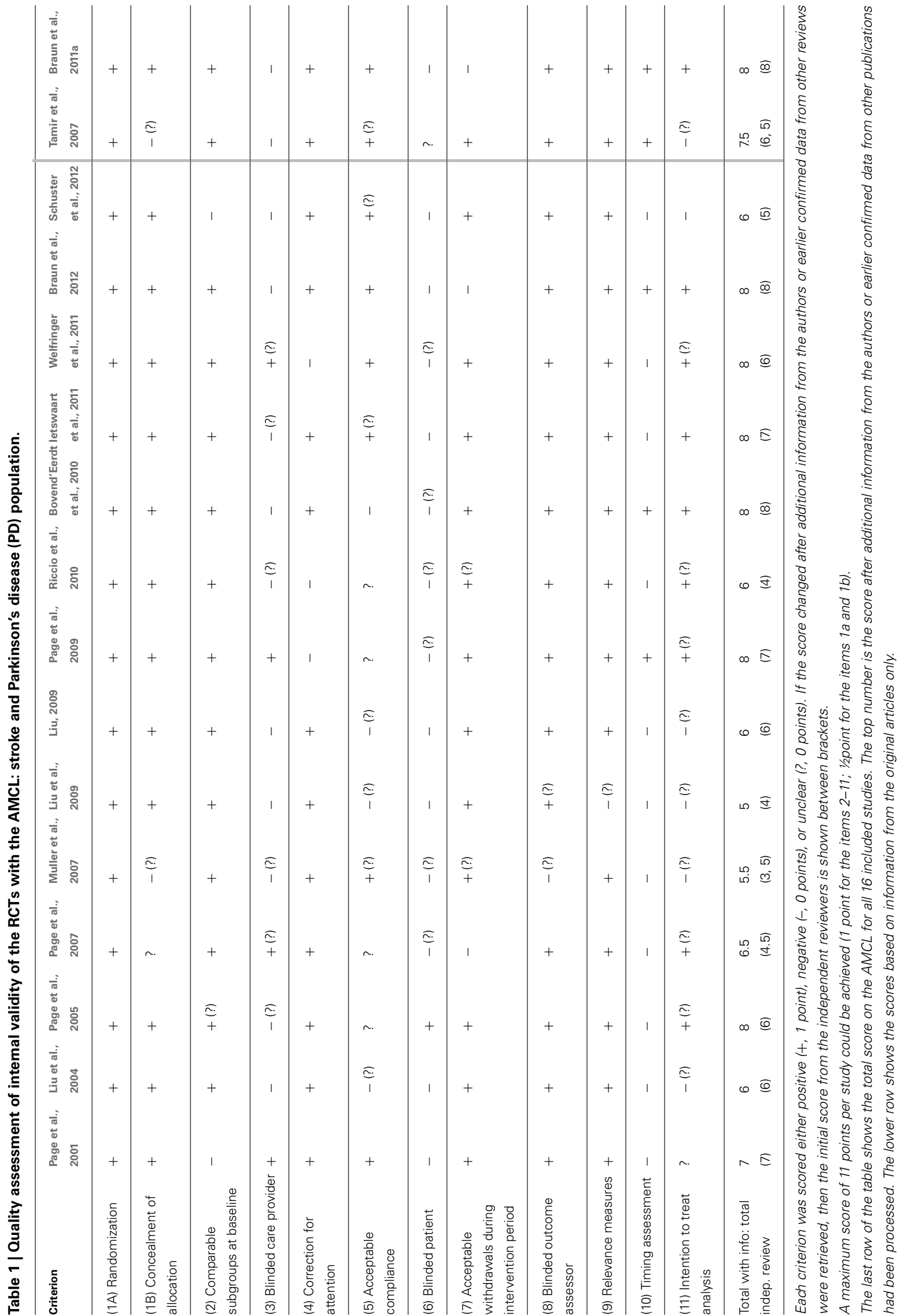




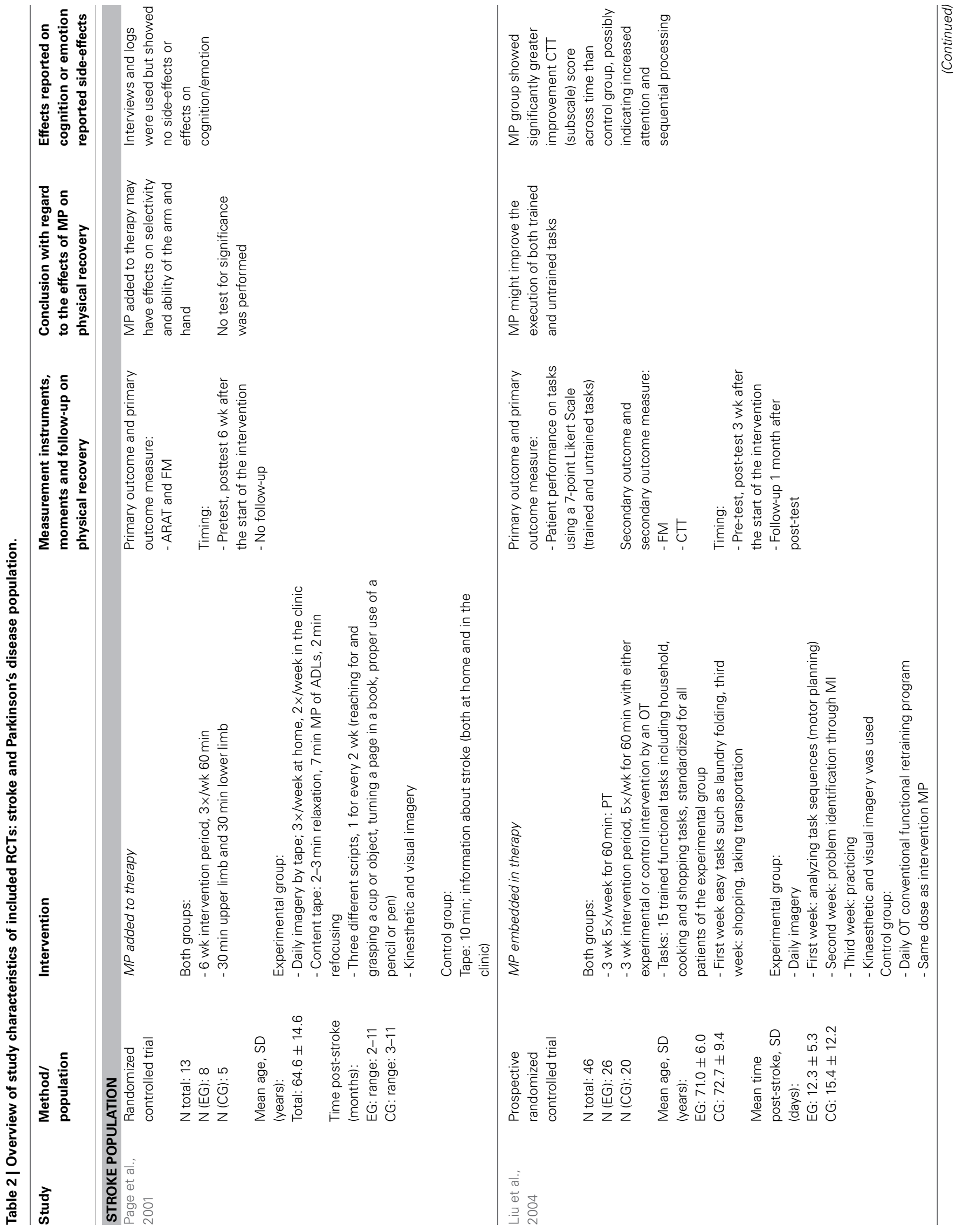




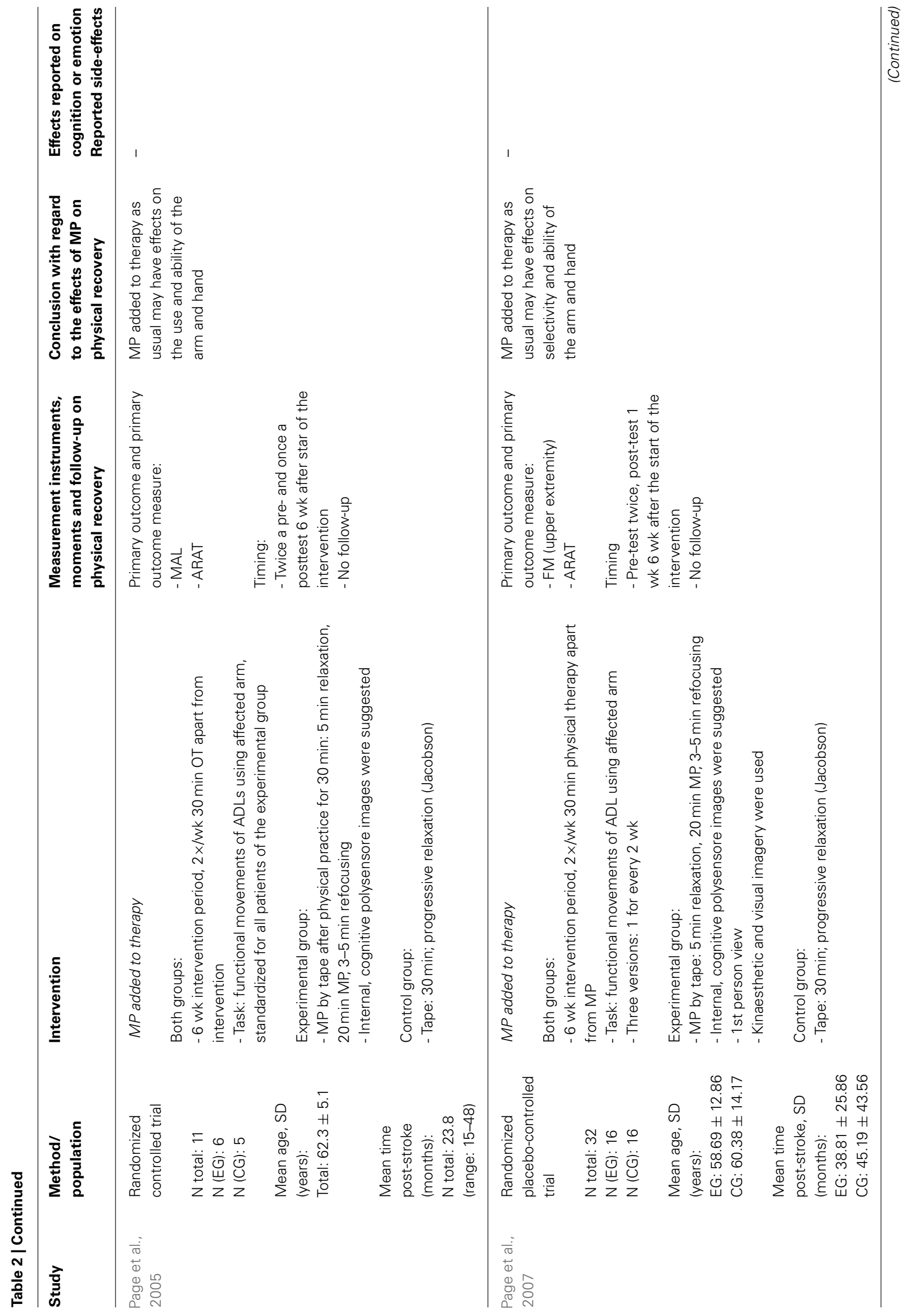



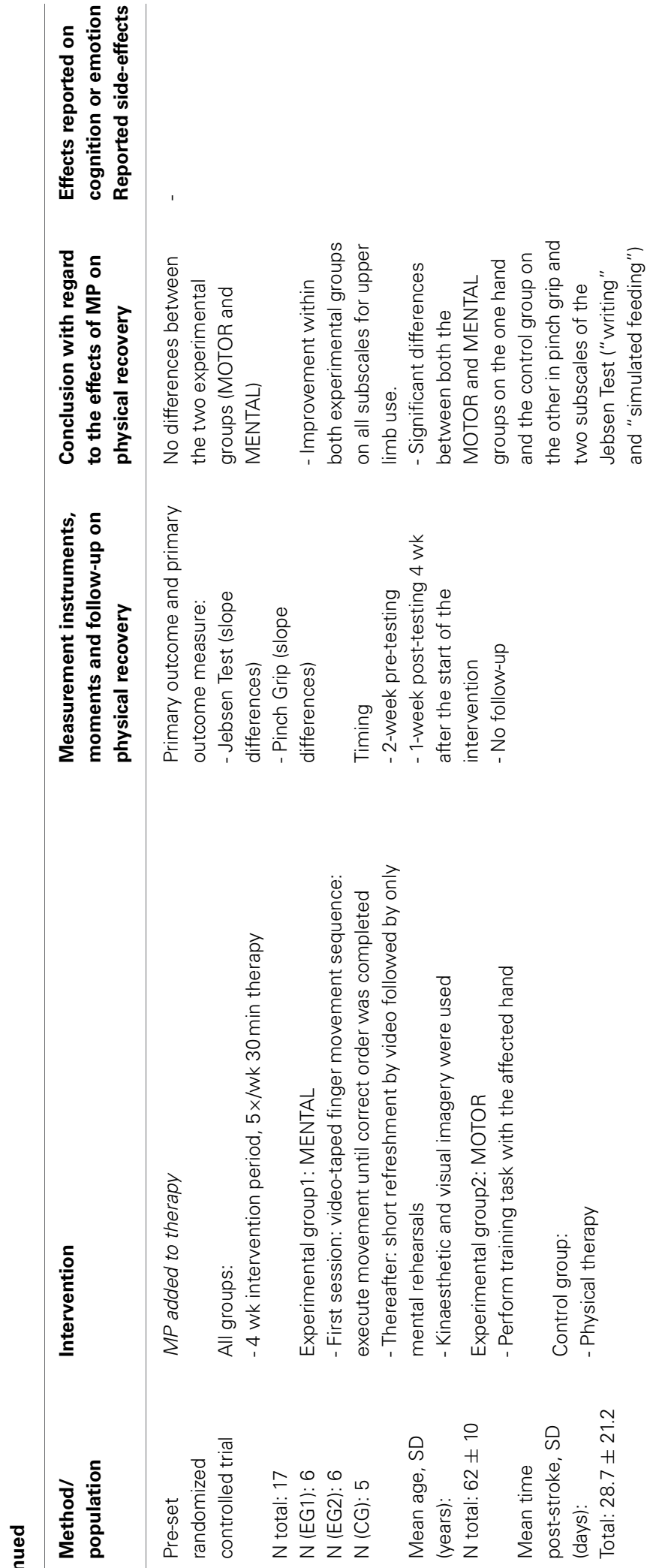
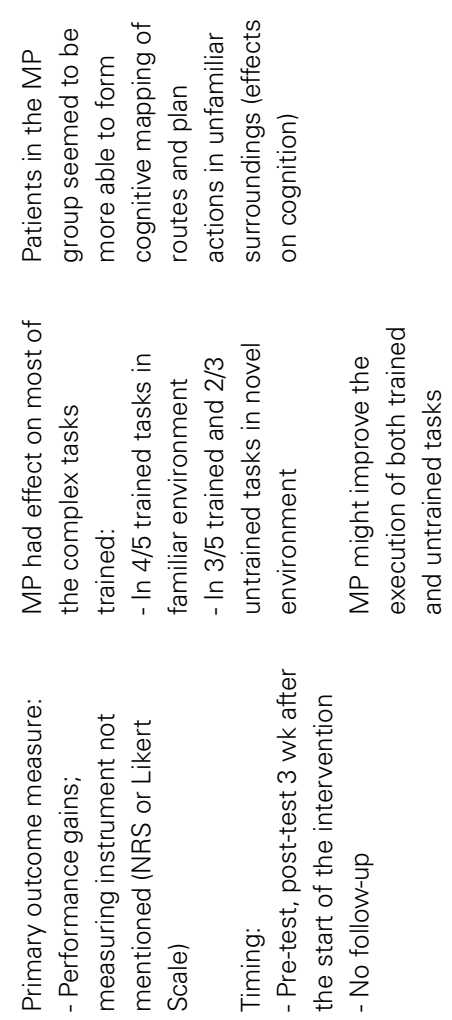

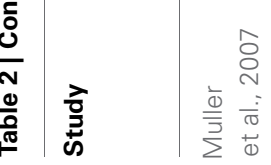




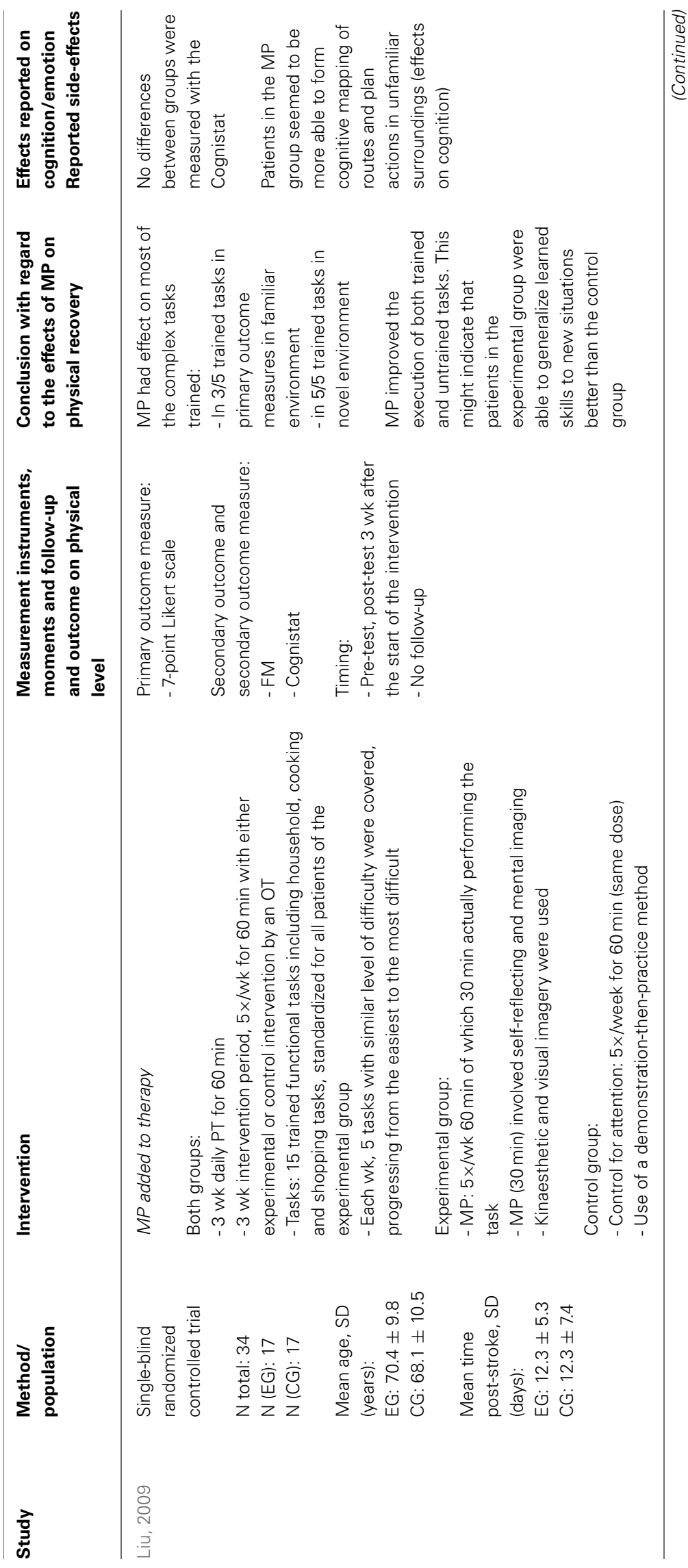




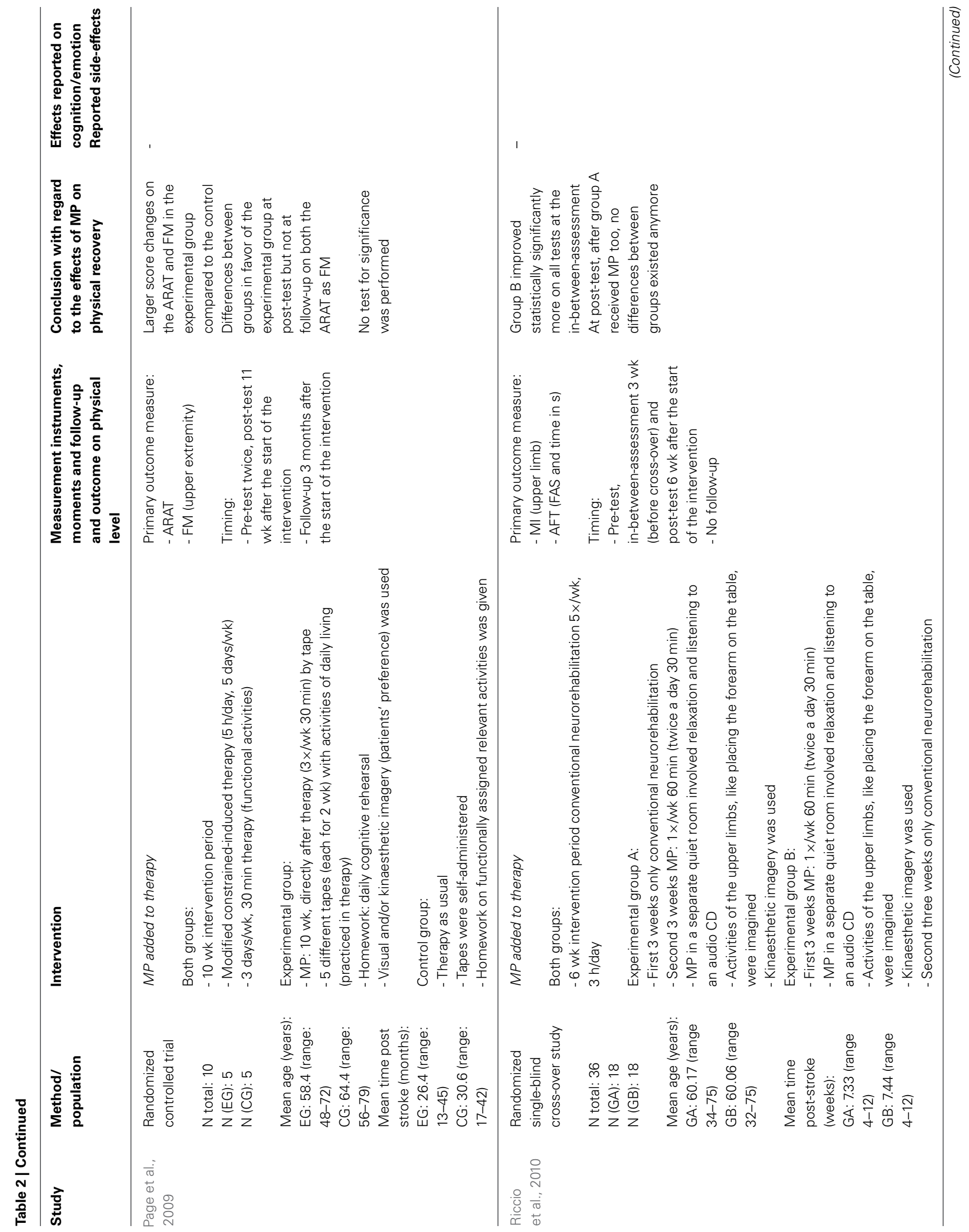




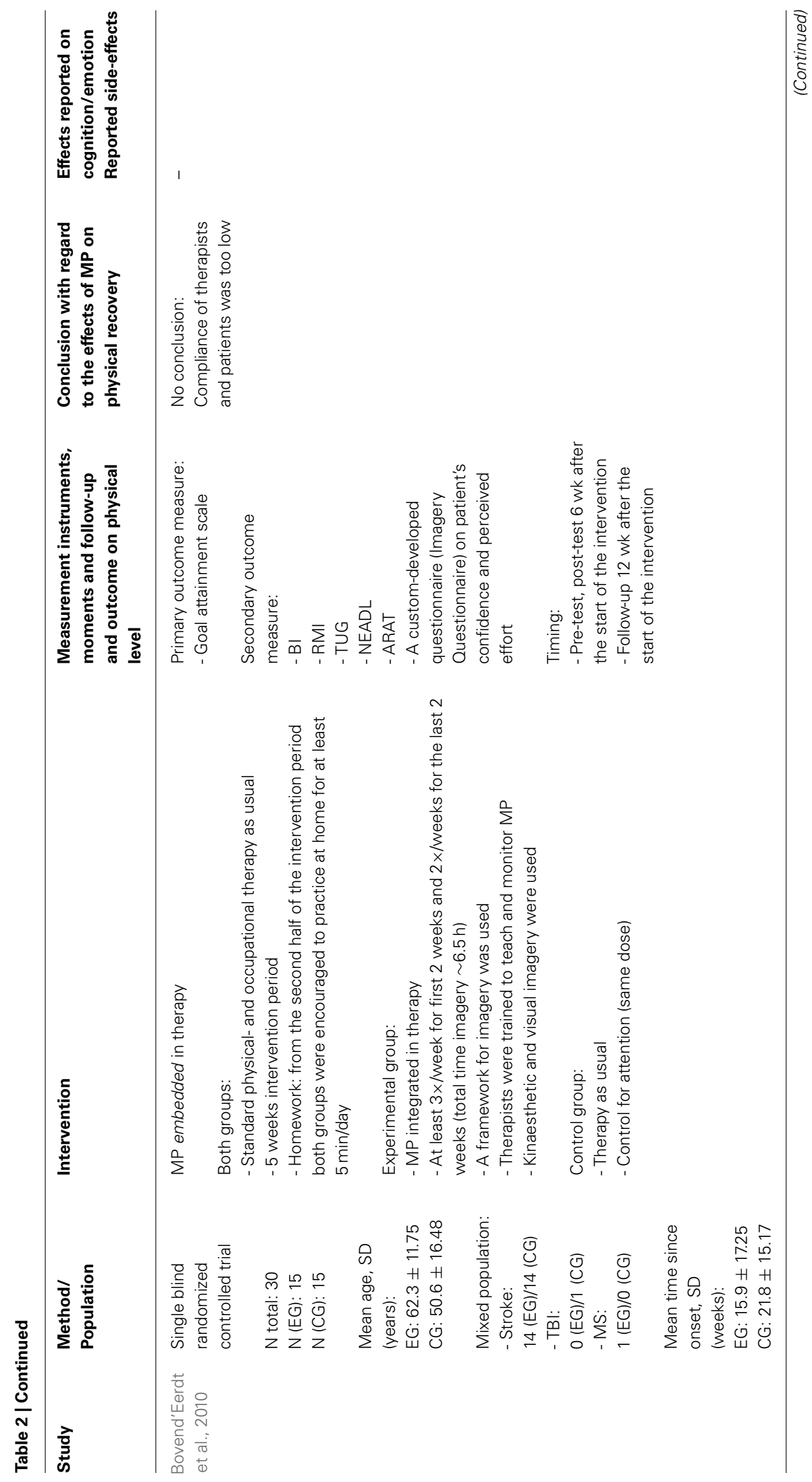



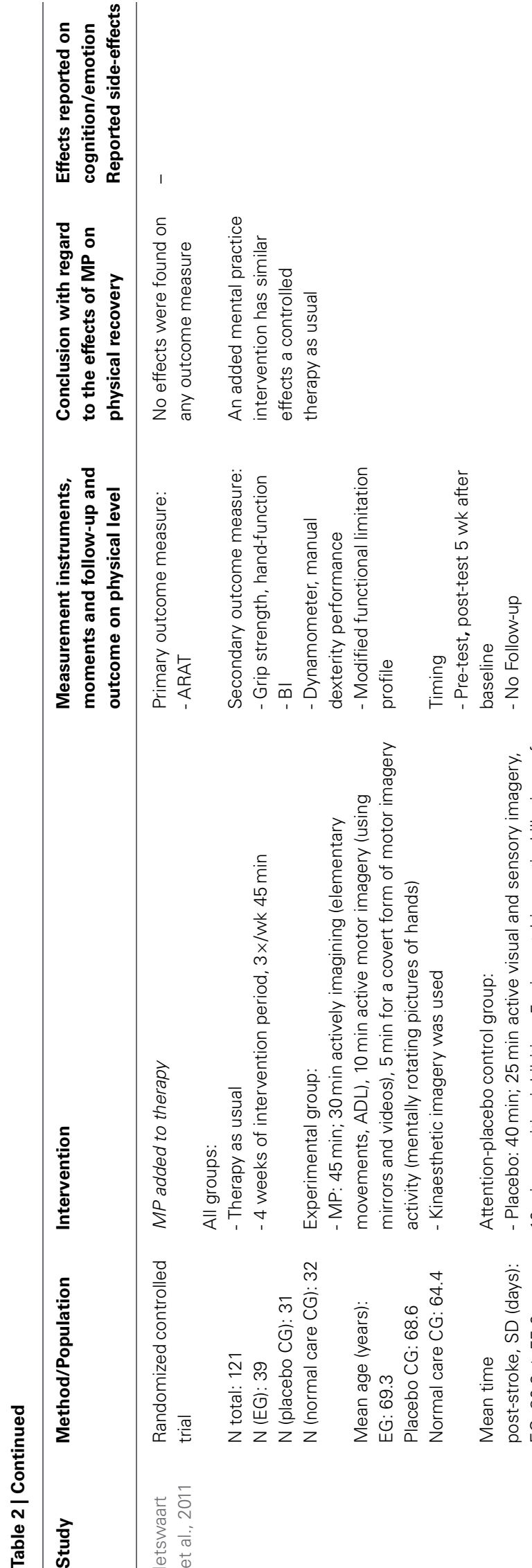

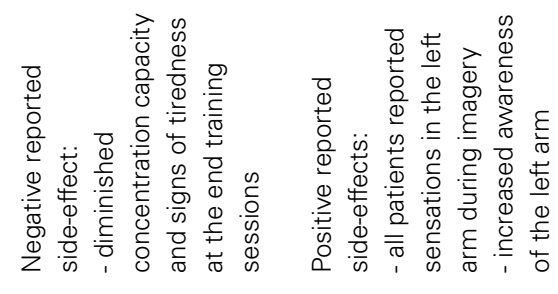

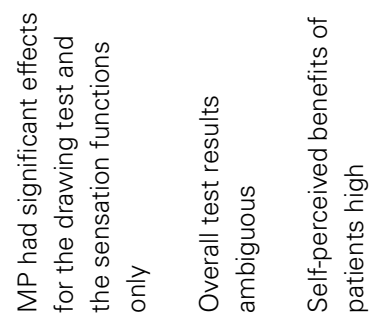
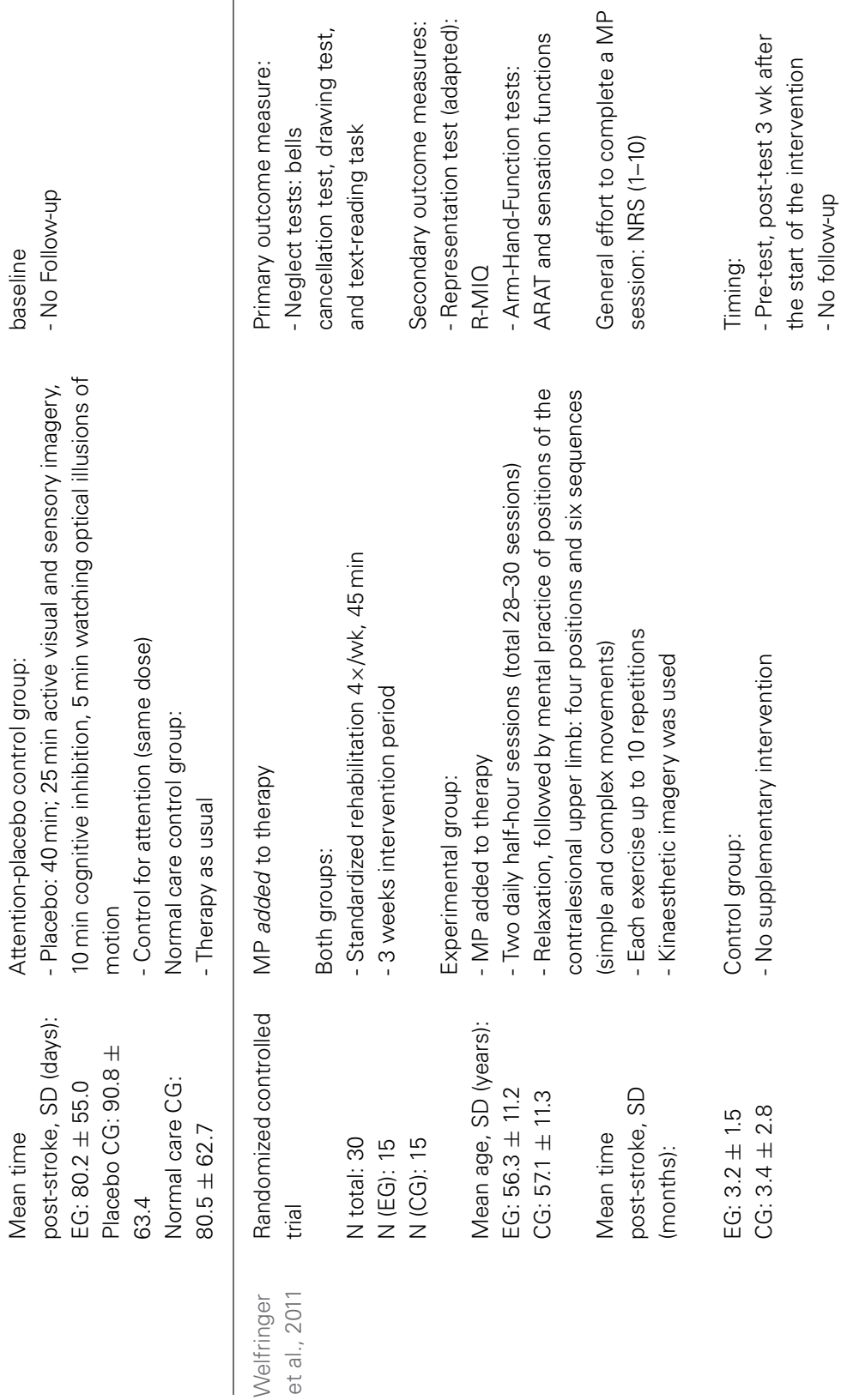

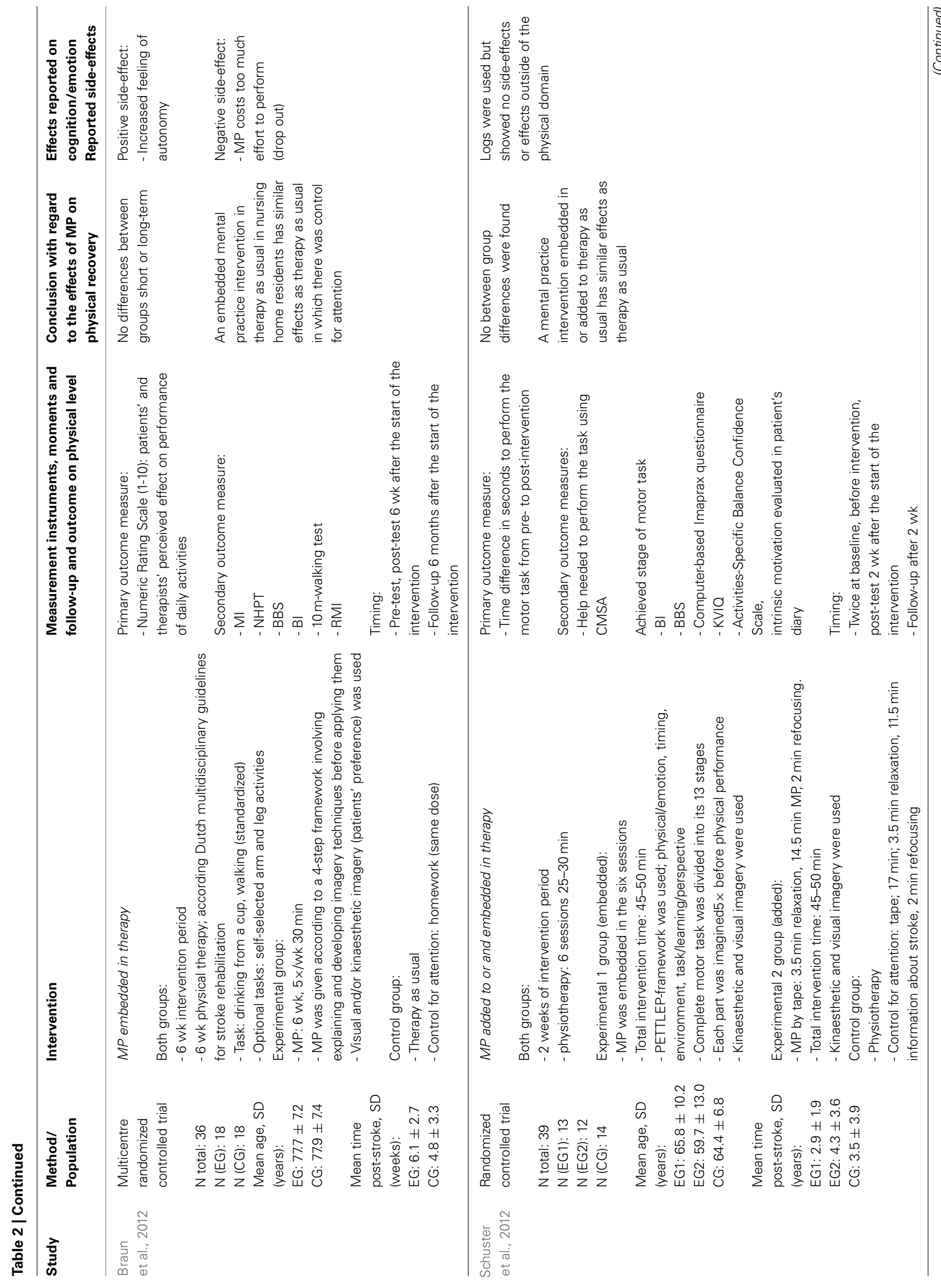


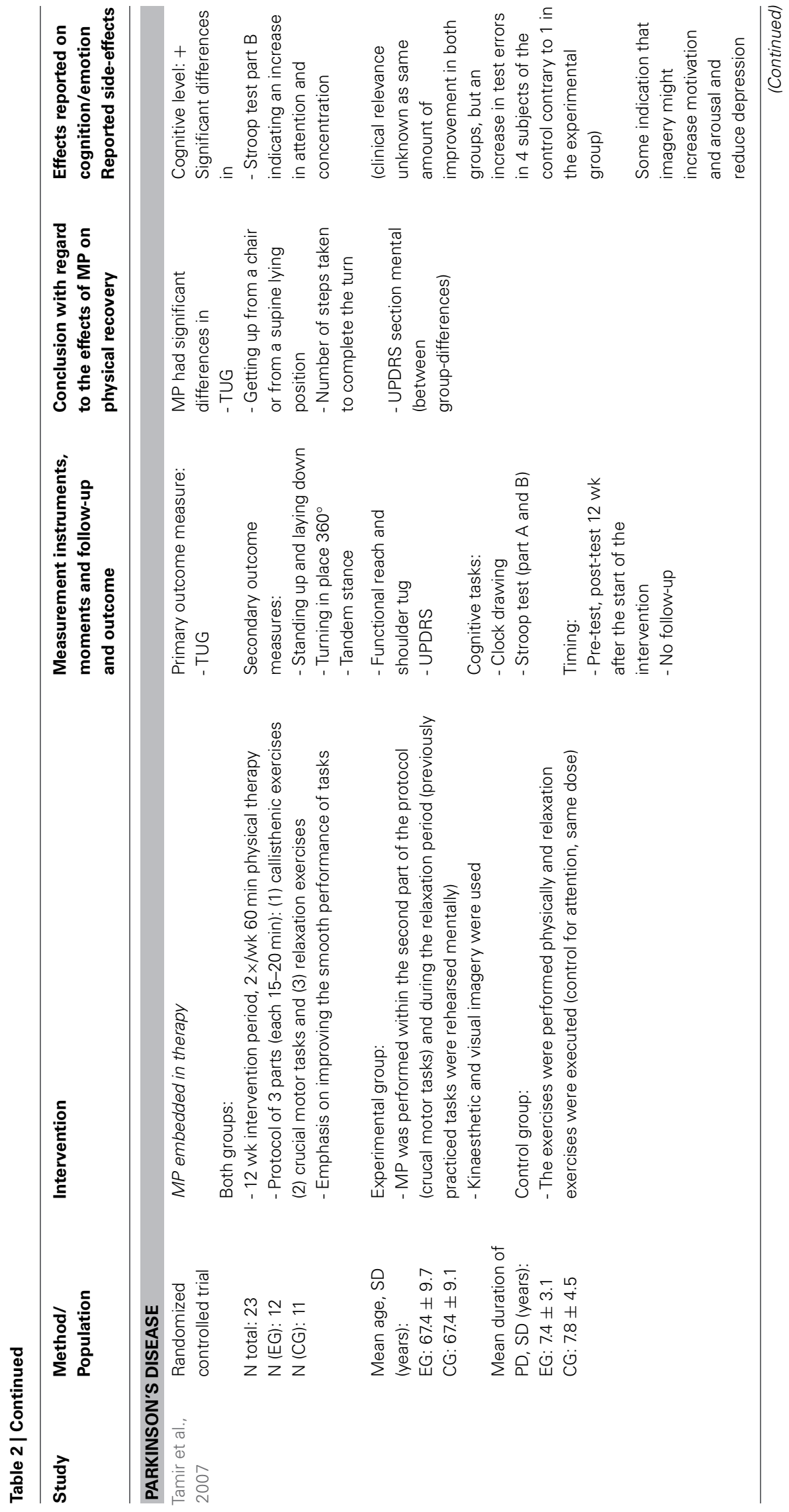




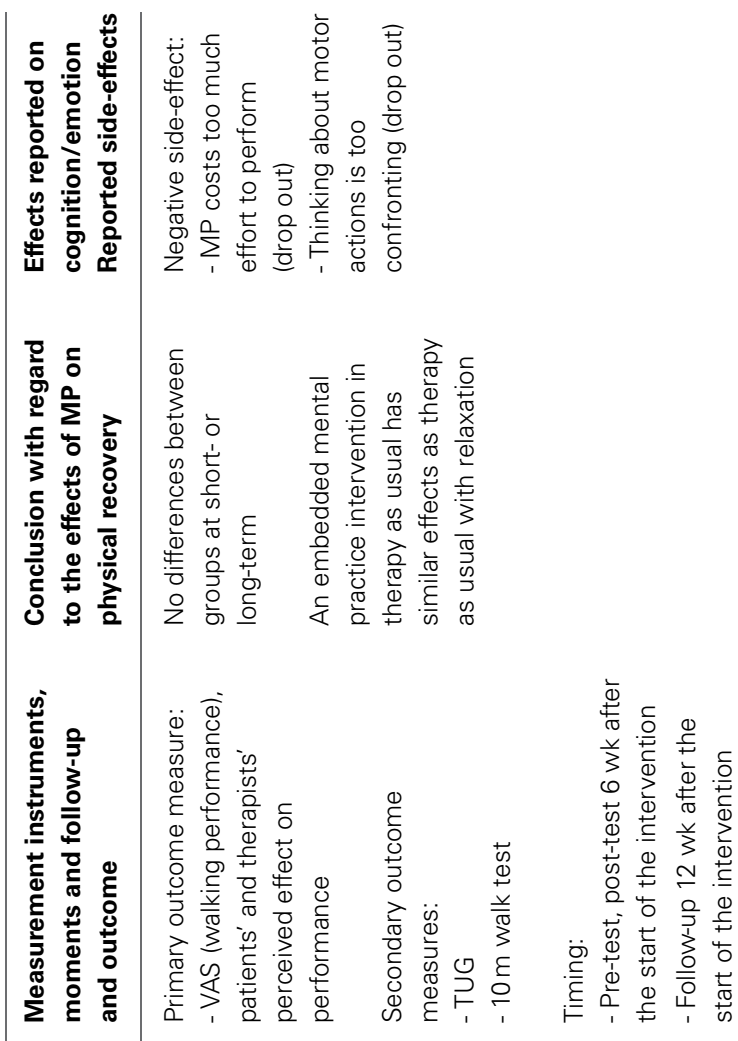

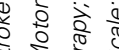

is $\sum$ क्ष

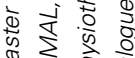

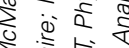

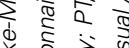

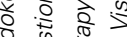

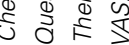

तो 칠

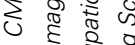

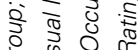

(1) 50

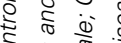

0.000

i.

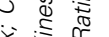

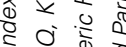

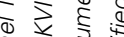

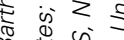

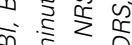

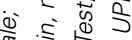

फ है के

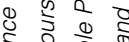

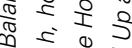

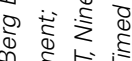

को

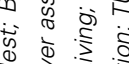

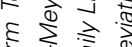

文 송

क्ष

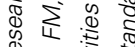

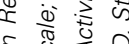

हो

安全

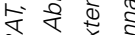

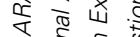

茛

का 专

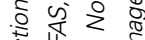

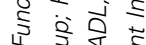

ह ㅇํㄹ है

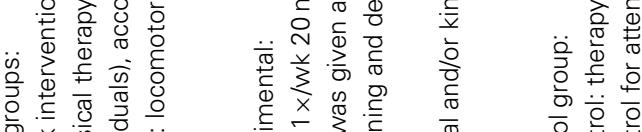

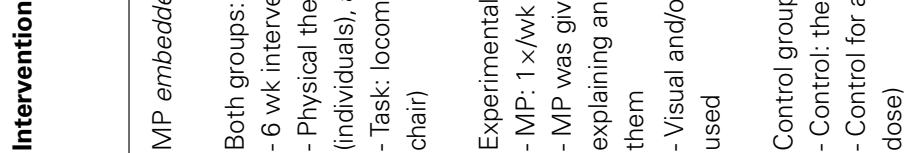

责

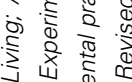

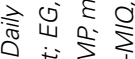

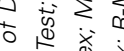

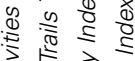

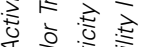

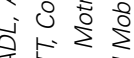

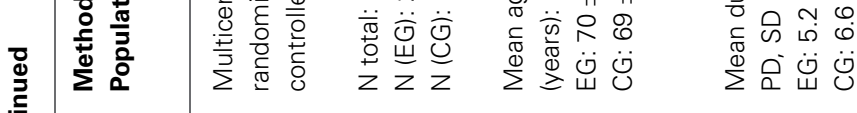

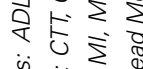

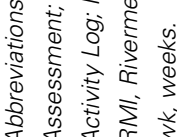


et al., 2007; Liu, 2009; Bovend'Eerdt et al., 2010; Braun et al., 2011a, 2012; Schuster et al., 2012).

Based on these qualitative descriptions it seems that different kind of interventions may have potential effects on activities (e.g., embedded and added mental practice were both reported effective and ineffective in different studies).

\section{EFFECTS ON COGNITION OR EMOTION AND SIDE-EFFECTS}

Five studies reported effects on cognition (Liu et al., 2004, 2009; Tamir et al., 2007; Liu, 2009; Welfringer et al., 2011) which were measured with the Stroop test (part B) in participants with Parkinson's disease (Tamir et al., 2007), the Color Trails Test (CTT; Liu et al., 2004) and the Cognistat (Liu, 2009) in participants after stroke (Table 2). Participants with Parkinson's disease seemed to have an increase in attention and concentration after the mental practice intervention period (Tamir et al., 2007). In the studies by Liu et al. (2004, 2009); Liu (2009) the mental practice intervention involved strategy training and participants after stroke seemed to be more able to form cognitive maps of routes and plan actions in unfamiliar surroundings compared to the participants in the control group. Earlier positive findings on the CTT were however not repeated in a later study using the Cognistat (Liu et al., 2004; Liu, 2009).

Positive observed side-effects reported in the stroke trials were increased autonomy (Braun et al., 2012) and increased sensations in and awareness of the left arm (Welfringer et al., 2011). In Parkinson's disease research there was some indication that imagery might increase motivation and arousal and reduce depression (Tamir et al., 2007).

Two studies reported acute adverse side-effects of mental practice (Braun et al., 2011a, 2012) like "too much effort," "not worthwhile," and "too confronting." Some participants after stroke showed diminished concentration and signs of tiredness at the end of mental practice training sessions (Welfringer et al., 2011).

\section{DATA SYNTHESIS OF THE META-ANALYSIS}

The meta-analysis was conducted using a selection of the studies in stroke in which the same physical outcome measurement instruments were used (Table 3).

A meta-analysis in participants with Parkinson's disease was not possible. Both studies use the Timed up and Go as an outcome measure, but Tamir et al. did not report the exact data (only figures provided; Tamir et al., 2007). Several outcome measures which had been used in at least two studies were excluded because of missing data (Motricity Index, Pinch/Hand force; Muller et al., 2007; Riccio et al., 2010). The study of Schuster et al. (2012) was excluded because of clinical important differences between groups at baseline. Six times data could pooled in a meta-analysis. No sensitivity test could be performed as all studies that could be pooled were of at least sufficient quality.

\section{RESULTS ON MOBILITY - RIVERMEAD MOBILITY INDEX}

Data were available from two studies (Bovend'Eerdt et al., 2010; Braun et al., 2012) that randomized a total of 64 and 58 participants respectively. Pooling did not lead to significant effects assessed with the Rivermead Mobility Index directly after the intervention ( $p=0.72 ; M D:-0.82 ; 95 \% C I:-3.04$ to 1.41 ) nor at follow-up ( $p=0.75 ; M D:-0.40 ; 95 \% C I:-2.90$ to 2.10 ).

\section{RESULTS ON ARM-FUNCTION-ACTION RESEARCH ARM TEST (FIGURE 2)}

Data were available from seven studies (Page et al., 2001, 2005, 2007, 2009; Bovend'Eerdt et al., 2010; Ietswaart et al., 2011; Welfringer et al., 2011) that randomized a total of 197 participants. Due to heterogeneity in the SDs of outcomes SMD and

Table 3 | Overview of used measure instruments that could potentially be used in pooling.

\begin{tabular}{|c|c|c|c|c|c|c|c|c|c|}
\hline Outcome & ARAT & Pinch & NRS/LS & $\mathbf{M I}$ & BBS & BI & $10 \mathrm{~m}$ & RMI & TUG \\
\hline \multicolumn{10}{|l|}{ STROKE } \\
\hline Page et al., 2001 & $x$ & & & & & & & & \\
\hline Liu et al., 2004 & & & $\times$ & & & & & & \\
\hline Page et al., 2005 & $\times$ & & & & & & & & \\
\hline Page et al., 2007 & $\times$ & & & & & & & & \\
\hline Muller et al., 2007 & & $\times$ & & & & & & & \\
\hline Liu et al., 2009 & & & $\times$ & & & & & & \\
\hline Liu, 2009 & & & $\times$ & & & & & & \\
\hline Page et al., 2009 & $x$ & & & & & & & & \\
\hline Riccio et al., 2010 & & & & $\times$ & & & & & \\
\hline Bovend'Eerdt et al., 2010 & $\times$ & & & & & $\times$ & & $\times$ & $\times$ \\
\hline letswaart et al., 2011 & $\times$ & $\times$ & & & & $\times$ & & & \\
\hline Welfringer et al., 2011 & $\times$ & & & & & & & & \\
\hline Braun et al., 2012 & & & $x$ & $x$ & $x$ & $x$ & $x$ & $x$ & \\
\hline Schuster et al., 2012 & & & & & $\times$ & $\times$ & & & \\
\hline \multicolumn{10}{|l|}{ PARKINSON'S DISEASE } \\
\hline Tamir et al., 2007 & & & & & & & & & $\times$ \\
\hline Braun et al., 2011a & & & $\times$ & & & & $\times$ & & $\times$ \\
\hline
\end{tabular}

Abbreviations: ARAT, Action Research Arm Test; NRS/LS, Numeric Rating Scale/Likert Scale; MI, Motricity Index; BBS, Berg Balance Scale; BI, Barthel Index; 10 m, $10 \mathrm{~m}$ walking test; RMI, Rivermead Mobility Index; TUG, Timed Up and Go. Gray Shading: Data could be pooled. 


\begin{tabular}{|c|c|c|c|c|c|c|c|c|c|}
\hline \multirow[b]{2}{*}{ Study or Subgroup } & \multicolumn{3}{|c|}{ Experimental } & \multicolumn{3}{|c|}{ Control } & \multicolumn{2}{|r|}{ Std. Mean Difference } & \multirow{2}{*}{$\begin{array}{l}\text { Std. Mean Difference } \\
\text { IV, Random, } 95 \% \mathrm{Cl}\end{array}$} \\
\hline & Mean & SD & Total & Mean & SD & Total & Weight & IV, Random, $95 \% \mathrm{Cl}$ & \\
\hline Bovend'Eerdt et al., 2010 & 31.7 & 24.97 & 15 & 30.7 & 23.38 & 15 & $18.2 \%$ & $0.04[-0.68,0.76]$ & $-\frac{1}{1-}$ \\
\hline letswaart et al., 2011 & 31.51 & 20.68 & 39 & 30.38 & 20.53 & 32 & $21.8 \%$ & $0.05[-0.41,0.52]$ & $-\frac{1}{1}$ \\
\hline Page et al., 2001 & 40.4 & 13.4 & 8 & 25 & 11.7 & 5 & $11.6 \%$ & $1.12[-0.11,2.35]$ & - \\
\hline Page et al., 2005 & 43.8 & 3.09 & 6 & 38.7 & 1.2 & 5 & $8.8 \%$ & $1.91[0.36,3.46]$ & \\
\hline Page et al., 2007 & 25.81 & 11.29 & 16 & 17.69 & 13.75 & 16 & $18.2 \%$ & $0.63[-0.08,1.34]$ & - \\
\hline Page et al., 2009 & 42.6 & 1.2 & 5 & 36.4 & 1.1 & 5 & $3.1 \%$ & $4.86[1.86,7.87]$ & \\
\hline Welfinger et al., 2011 & 9.6 & 18.5 & 15 & 6.5 & 16.2 & 15 & $18.2 \%$ & $0.17[-0.54,0.89]$ & - \\
\hline Total $(95 \% \mathrm{Cl})$ & & & 104 & & & 93 & $100.0 \%$ & $0.62[0.05,1.19]$ & 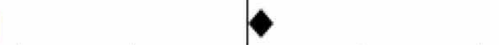 \\
\hline \multicolumn{7}{|c|}{$\begin{array}{l}\text { Heterogeneity: } \text { Tau }^{2}=0.33 ; \mathrm{Chi}^{2}=17.14, \mathrm{df}=6(\mathrm{P}=0.009) ; \mathrm{I}^{2}=65 \% \\
\text { Test for overall effect: } Z=2.13(\mathrm{P}=0.03)\end{array}$} & & & $\begin{array}{lcccc} & 1 & & 1 & \\
-10 & -5 & 0 & 5 & 10 \\
& \text { Favours control } & \text { Favours experimenta }\end{array}$ \\
\hline
\end{tabular}

random-effect model were used. Pooling led to significant shortterm effects on the Action Research Arm Test ( $p=0.03 ; S M D$ 0.62; $95 \% C I: 0.05$ to 1.19 ). No data for long-term effects could be pooled.

\section{RESULTS ON FUNCTIONING IN ACTIVITIES OF DAILY LIVING-BARTHEL INDEX}

Data of the Barthel Index were available from three studies (Bovend'Eerdt et al., 2010; Ietswaart et al., 2011; Braun et al., 2012) on short-term that randomized a total of 135 participants. Pooling did not show significant effects $(p=0.31 ; M D: 0.87 ; 95 \%$ $C I$ : -0.80 to 2.53$)$. No significant effects were found at follow-up either ( $p=0.75$; MD:0.46; 95\% CI: -2.36 to 3.27). Data for long-term effects were available from two studies (Bovend'Eerdt et al., 2010; Braun et al., 2012) that randomized a total of 57 participants. The study of Liu (Liu et al., 2009) used the modified Barthel Index and was therefore excluded from pooling in both meta-analyses.

\section{RESULTS FROM FUNCTIONAL ACTIVITIES—NUMERIC RATING SCALE (FIGURE 3)}

Four studies (Liu et al., 2004, 2009; Liu, 2009; Braun et al., 2012) used a numeric rating scale to assess the performance of functional activities. Two studies were excluded from the analyses because they did not provide any point estimates (Liu, 2009; Liu et al., 2009). The data of the studies by Braun et al. and Liu et al. were pooled using SMD because Braun et al. (2012) used a 10point scale whereas Liu et al. (2004) used a 7-point scale. Liu et al. provide data of the average score of five activities that was used for the analyses. Braun et al. provided scores of the NRS of drinking, walking, and two self-chosen activities. We used the data of the most promising result (biggest different between the experimental and the control group) this was the score of the self-chosen activity for the lower limb. Data of 78 participants could be pooled and a marginal significant overall effect on shortterm was found. ( $p=0.04 ; S M D 0.9 ; 95 \% C I$ : 0.04 to 1.77$)$. No long-term data could be pooled.

\section{DISCUSSION}

This present review included 16 randomized controlled trials (14 in stroke and two in Parkinson's disease) involving 491 participants (of which 70 in Parkinson's disease) and shows some benefits of a mental practice intervention on arm hand ability (Page et al., 2001, 2005, 2007, 2009; Bovend'Eerdt et al., 2010; Ietswaart et al., 2011; Welfringer et al., 2011) and mobility (Liu et al., 2004; Braun et al., 2012) after stroke. Of the 14 identified studies only 6 showed overall effects in favor of mental practice.

No firm conclusions can be drawn from the existing evidence with regard to the effectiveness of mental practice in participants with Parkinson's disease. No randomized controlled trials within the multiple sclerosis target group were found. Two recently published non-randomized studies investigated the mental practice ability of patients with multiple sclerosis (Heremans et al., $2012 \mathrm{a}, \mathrm{b})$. There seems to be a potential use of mental practice in patients with multiple sclerosis. The studies reported in this review remain small (sub groups ranging from 5 to 39 participants), the populations studied vary greatly in most clinical domains, and the outcomes studied also differ a lot. The methodologic quality of the studies ranged from 3.5 to 8 points on the AMCL assessment scale after blinded assessment and also after additional information from the authors was taken into account. This review also finds some evidence for effects on cognition and emotion (e.g., effects on attention, plan actions in unfamiliar surroundings) and reports several observed sideeffects (e.g., might increase motivation and arousal and reduce depression, but may also lead to diminished concentration and irritation).

Four recent zero trials (Bovend'Eerdt et al., 2010; Ietswaart et al., 2011; Braun et al., 2012; Schuster et al., 2012) have been added to the body of knowledge on mental practice $(n=$ 226), accounting for about half of the total number of participants within all 14 included trials in stroke. Within these zero trials the sample sizes are bigger and more heterogeneous. In addition, more measures on activity level in more general sense were used within these later trials (Barthel Index, BI, and Rivermead Mobility Index, RMI). One could hypothesize that the effects of mental practice are mainly related to aspects as velocity, precision, and coordination of a movement. Improvement in these specific effects of mental practice are perhaps not or hardly detectable with these more generic measures contrary to f.i. the ARAT. In the ARAT and the NRS meta-analyses 


\begin{tabular}{|c|c|c|c|c|c|c|c|c|c|}
\hline \multirow[b]{2}{*}{ Study or Subgroup } & \multicolumn{3}{|c|}{ Experimental } & \multicolumn{3}{|c|}{ Control } & \multicolumn{2}{|r|}{ Std. Mean Difference } & \multirow{2}{*}{$\begin{array}{c}\text { Std. Mean Difference } \\
\text { IV, Random, } 95 \% \mathrm{Cl}\end{array}$} \\
\hline & Mean & SD & Total & Mean & SD & Total & Weight & IV, Random, $95 \% \mathrm{Cl}$ & \\
\hline Braun et al., 2012 & 7.19 & 1.6 & 16 & 6.38 & 1.9 & 16 & $48.8 \%$ & $0.45[-0.25,1.15]$ & +- \\
\hline Liu et al., 2004 & 5.3 & 1 & 26 & 4 & 0.9 & 20 & $51.2 \%$ & $1.33[0.68,1.98]$ & - \\
\hline Total $(95 \% \mathrm{Cl})$ & & & 42 & & & 36 & $100.0 \%$ & $0.90[0.04,1.77]$ & \\
\hline \multicolumn{9}{|c|}{$\begin{array}{l}\text { Heterogeneity: Tau }{ }^{2}=0.27 ; \mathrm{Chi}^{2}=3.28, \mathrm{df}=1(\mathrm{P}=0.07)_{;} \mathrm{I}^{2}=70 \% \\
\text { Test for owerall effect: } \mathrm{Z}=2.04(\mathrm{P}=0.04)\end{array}$} & $\begin{array}{ccccc}-4 & -2 & 0 & 2 & 4 \\
\text { ivours experimental } & \text { Favours control }\end{array}$ \\
\hline
\end{tabular}

outcome of both zero and positive trials were pooled, leading to small effect sizes for mental practice in these outcome measures.

Imagery research is still booming and after our search was completed (June 2012) results of new trials were published (f.i. two recent studies on the effects of imagery on gait (Cho et al., 2012; Guttman et al., 2012)). These studies however remain relatively small, but adding new trials to the models could still overturn the results (Langhorne et al., 2009).

\section{STUDY LIMITATIONS}

There is a possibility that studies were missed due to inconsistency in terminology used in databases (e.g., mental practice, motor imagery, movement imagery).

The varied clinical populations in this review can be seen as a limitation. This review however does summarize the existing information in neurorehabilitation about a widely used intervention, which will facilitate the exchange of existing knowledge and evidence between professionals working with different target populations. Reviews covering the evidence for specific interventions in multiple target groups, like the recently published one by Newman and Barker (2012) on supported standing, will help professionals get a better understanding of the intervention and potential (side-) effects.

Using assessment scales in general and therefore also the AMCL for rating methodologic quality leads to some practical issues. Blinding of therapists and patients is often not possible in therapeutic interventions like mental practice. If therapists instruct the patients they are not blind to the type of intervention they are providing. The same accounts for the patients when they are asked to actively participate in an intervention. In randomized controlled trials in which therapeutic interventions (e.g., physiotherapy and occupational therapy) are researched the assessment of the randomized controlled trials with any assessment scale will be lower than in for instance pharmaceutical studies. The highest possible score on the AMCL of 11 points will decrease in many therapeutic studies by 2 points, as double blinding is often not possible.

Different assessment tools were used to rate the quality of the included studies (PEDro (Nilsen et al., 2010; BarclayGoddard et al., 2011), AMCL (Braun et al., 2006), JADAD (Cha et al., 2012)) in earlier reviews. The PEDRO and AMCL are derived from the Delphi list and therefore interrelated (Olivo et al., 2008). The JADAD is a shorter list, most used even though it was not originally developed for therapeutic studies (Olivo et al., 2008). Sometimes the studies within the reviews were categorized into lower and high quality studies (Braun et al., 2006; Zimmermann-Schlatter et al., 2008; Cha et al., 2012) and sometimes the authors of trials were contacted to provided additional information (Barclay-Goddard et al., 2011).

We contacted the authors to clarify the criteria on which a question mark was scored after the blinded reviewing assessment by the independent reviewers was performed. The quality assessment of identical studies may therefore vary within the different reviews as scores on assessment tools normally go up after additional information is retrieved. In one review the quality criteria for assessment of the identified studies were chosen by the reviewers (Zimmermann-Schlatter et al., 2008). These differences make it harder to compare the results and recommendations from the reviews.

Good reporting of trials is important to understanding changes and effects of mental practice and therefore ongoing attention to high quality study reports is required (BarclayGoddard et al., 2011). Guidelines, like the CONSORT statements are essential to achieve this.

The biggest problem of researching mental practice is the lack of consensus on the definition and concept of the intervention. Heterogeneity within the intervention protocols and outcomes makes it impossible to conduct an overall pooling and thus to come to an overall conclusion.

Results from pooling based on identical outcome measures should be interpreted with caution because of the heterogeneity in study populations. Also, results from meta-analyses depend very much on the data (and models) used. We decided to base the decision on which model to use on the measurement instruments (identical instruments or instruments measuring the same construct) and on the variance in SDs across the included studies. The downside of this flexibility in data/model choice is that it is harder for the reader to follow what has been done in the analysis. The biggest and in our opinion more important advantage is that the outcome is less misleading. Big variation in SDs across studies reflect differences in the real variability of outcomes and the use of MD would in our case suggest potential effects which are probably not there. The study by Ietswaart et al. (2011) with the largest population would for instance have the lowest weight in the meta-analysis and studies with relatively small sample sizes would determine outcome for more than $80 \%$. We tried to correct 
for this heterogeneity in the analysis and we used change scores instead of effect sizes which might explain to some extend why our results are less optimistic than the meta-analysis by Cha et al. (2012). In the meta-analysis by Cha et al. mental practice combined with exercise therapy had an even bigger effect size (ES 0.51; moderate) then augmented therapy alone (Cha et al., 2012). Two other reviews (Nilsen et al., 2010; Barclay-Goddard et al., 2011) performed statistical analyses to synthesize the evidence of six (Barclay-Goddard et al., 2011) and four (Nilsen et al., 2010) studies. Differences in statistical analysis approaches should be taken into account when interpreting and comparing the results.

Publication bias is a potential weakness in all systematic reviews, as positive or statistically significant findings are more likely to be published than small trials with non-significant or negative findings (Thornton and Lee, 2000). The funnel plot of the ARAT showed indication for publication bias (results not presented) and should therefore be interpreted with care. Barclay-Goddard et al. (2011) identified some risk of bias with regard to concealment of allocation and blinding. Cha et al. (2012) did not report any significant publication bias in their investigation.

\section{STRENGTHS AND LIMITATIONS OF PAST STUDIES}

Determining effects of complex interventions like mental practice is complicated (Braun et al., 2011b). A systematic way of assessing the potential of mental practice could be through the four steps suggested by the Medical Research Council (Craig et al., 2008). Until now, most research has been performed in the first two steps of this model: "determining the working mechanisms" and "piloting." Fundamental research has shown that mental practice can be performed in patients with neurological conditions and showed that the underlying mechanism is also working in at least parts of the patient populations.

The past 5 years more research has been published on techniques that might assist in monitoring and implementing imagery treatments, like tests (e.g., chronometry, hand-rotationtest; Malouin et al., 2008a; Simmons et al., 2008) and questionnaires (e.g., KVIQ; Malouin et al., 2007, 2008b). Mental practice has been explored in different clinical situations and contexts and a range of different types of intervention, assessed with different measures, have been studied. However, the predictive value of these tests has not been established yet. So we do not know for sure if people who can image according to questionnaires and tests will also benefit from it and whether participants who are at first unable to image, are able to learn and potentially benefit

\section{REFERENCES}

Australian Stroke Foundation. (2010). Clinical Guidelines for Stroke Management. A Quick Guide for Occupational Therapy. Melbourne, VIC: Australian Stroke Foundation. Available online at: http://strokefoundation.com.au/site/ media/NSF_concise_guidelines_occu pational_therapy_2010.pdf (Accessed November 20, 2012).

Barclay-Goddard, R. E., Stevenson, T. J., Poluha, W., and Thalman, L.
(2011). Mental practice for treating upper extremity deficits in individuals with hemiparesis after stroke. Cochrane Database Syst. Rev. CD005950. doi: 10.1002/14651858. CD005950.pub4

Bovend'Eerdt, T. J., Dawes, H., and Sackley, C. (2010). An integrated motor imagery program to improve functional task performance in neurorehabilitation: a singleblind randomized controlled trial. Arch. Phys. Med. Rehabil. 91,

from imagery. In addition, if imagery tests are used as a selection tool patients who are unable to perform these tests are often excluded from research. That is why the study by Welfringer et al. (2011) is of value. Although the results should be interpreted with great caution because participants in the control group did not receive supplementary therapy on top of therapy as usual to control for mental practice, it is until now the only mental practice randomized controlled trial in patients with neglect. Researching feasibility and effects in sub groups that are normally excluded from research will tell us more about whether mental practice can be taught and who might benefit.

There are general methodologic issues in rehabilitations trials (Dobkin, 2007) that also should be considered in mental practice studies. The main problem is that almost all studies are underpowered, increasing the chance of type-2 errors. Especially in mono-centered, small trials the samples are not likely to reflect the real-world sample.

\section{RECOMMENDATIONS FOR THE DESIGN OF FUTURE TRIALS}

Recent negative trials have shown that not all participants with stroke and Parkinson's disease benefit from mental practice. At this point we do not know how to identify the people who might benefit from mental practice. Sample sizes of future trials should be large enough to enable sub group and dose-response analyses. For dose-response analyses adherence, attendance, and compliance should be reported (Barclay-Goddard et al., 2011). Especially adherence and compliance are difficult to assess as mental practice is an intervention that takes place in the mind and remains covert for the therapist. For adherence to mental practice it is essential that participants can engage in movement imagery. However, there is no perfect test to assess this ability. Combining some tests might provide indicators which then might be related to outcome. Therefore, the imagery ability of every participant should be assessed before and/or after the mental practice intervention.

The mental practice intervention should be well described. Both, short- and long-term effects should be measured with predefined measure instruments to enable comparison of results among different studies. Effects should not only be sought at the physical level, but also on emotion and cognition (Nilsen et al., 2010; Barclay-Goddard et al., 2011). Reporting the opinions on and experiences with mental practice of people with neurological diseases, care-givers, and care professionals will provide valuable information on how to optimize and tailor the mental practice intervention to the patients' needs and abilities. Mixed methods are needed to assess these different components.

939-946. doi: 10.1016/j.apmr.2010. 03.008.

Braun, S. M., Beurskens, A. J., Borm, P. J., Schack, T., and Wade, D. T. (2006). The effects of mental practice in stroke rehabilitation: a systematic review. Arch. Phys. Med. Rehabil. 87, 842-852. doi: 10.1016/j.apmr.2006.02.034

Braun, S. M., Beurskens, A. J., Kleynen, M., Oudelaar, B., Schols, J. M., and Wade, D. T. (2012). A multicenter randomized controlled trial to compare subacute "Treatment As Usual" with and without mental practice among persons with stroke in Dutch nursing homes. J. Am. Med. Dir. Assoc. 13, 85.e1-85.e7.

Braun, S. M., Beurskens, A. J., Kleynen, M., Schols, J. M., and Wade, D. T. (2011a). Rehabilitation with mental practice has similar effects on mobility as rehabilitation with relaxation in people with Parkinson's disease: a multicentre randomised trial. 
J. Physiother. 57, 27-34. doi: 10.1016/S1836-9553(11)70004-2

Braun, S. M., Wade, D. T., and Beurskens, A. J. (2011b). Use of movement imagery in neurorehabilitation: researching effects of a complex intervention. Int. J. Rehabil. Res. 34, 203-208. doi: 10.1097/MRR.0b013e328348b184

Cha, Y. J., Yoo, E. Y., Jung, M. Y., Park, S. H., and Park, J. H. (2012). Effects of functional task training with mental practice in stroke: a meta analysis. Neurorehabilitation 30, 239-246.

Cho, H. Y., Kim, J. S., and Lee, G. C. (2012). Effects of motor imagery training on balance and gait abilities in post-stroke patients: a randomized controlled trial. Clin. Rehabil. doi: 10.1177/0269215512 464702. [Epub ahead of print].

Craig, P., Dieppe, P., and Macintyre, S. (2008). Developing and evaluating complex interventions: the new Medical Research Counsil guidance. BMJ 337:a1655. doi: 10.1136/bmj. a 1655

Cunnington, R., Egan, G. F., O'Sullivan, J. D., Hughes, A. J., Bradshaw, J. L., and Colebatch, J. G. (2001). Motor imagery in Parkinson's disease: a PET study. Mov. Disord. 16, 849-857. doi: 10.1002/mds.1181

de Vries, S., and Mulder, T. (2007). Motor imagery and stroke rehabilitation: a critical discussion. J. Rehabil. Med. 39, 5-13. doi: 10.2340/16501977-0020

Dijkerman, H. C., Ietswaart, M., Johnston, M., and MacWalter, R. S. (2004). Does motor imagery training improve hand function in chronic stroke patients? A pilot study. Clin. Rehabil. 18, 538-549. doi: 10.1191/0269215504cr769oa

Dobkin, B. H. (2007). Confounders in rehabilitation trials of taskoriented training: lessons from the designs of the EXCITE and SCILT multicenter trials. Neurorehabil. Neural Repair 21, 3-13. doi: $10.1177 / 1545968306297329$

Evers, S. M., Struijs, J. N., Ament, A. J., van Genugten, M. L., Jager, J. H., and van den Bos, G. A. (2004). International comparison of stroke cost studies. Stroke 35, 1209-1215. doi: 10.1161/01.STR. 0000125860.48180 .48

Findley, L. J. (2007). The economic impact of Parkinson's disease. Parkinsonism Relat. Disord. 13(Suppl.), S8-S12. doi: 10.1016/j.parkreldis.2007.06.003

Freeman, L., Cohen, L., Stewart, M., White, R., Link, J., Palmer, J. L., et al. (2008). The experience of imagery as a post-treatment intervention in patients with breast cancer: program, process and patient recommendations. Oncol. Nurs. Forum 35, 116-121. doi: 10.1188/08.ONF. E116-E121

Guttman, A., Burstin, A., Brown, R. Bril, S., and Dickstein, R. (2012). Motor imagery practice for improving sit to stand and reaching to grasp in individuals with poststroke hemiparesis. Top. Stroke Rehabil. 19, 306-319. doi: 10.1310/tsr1904-306

Heremans, E., Nieuwboer, A., Spildooren, J., De Bondt, S., D'Hooge, A. M., Helsen, W., et al. (2012a). Cued motor imagery in patients with multiple sclerosis. Neuroscience 206, 115-121. doi: 10.1016/j.neuroscience.2011.12.060

Heremans, E., D'Hooge, A. M. De Bondt, S., Helsen, W., and Feys, P. (2012b). The relation between cognitive and motor dysfunction and motor imagery ability in patients with multiple sclerosis. Mult. Scler. 18, 1303-1309.

Huibers, M. J., Beurskens, A. J., Bleijenberg, G., and van Schayck, C. P. (2003). The effectiveness of psychosocial interventions delivered by general practitioners. Cochrane Database Syst. Rev. CD003494. doi: 10.1002/14651858.CD003494

Hwang, S., Jeon, H. S., Yi, C. H., Kwon, O. Y., Cho, S. H., and You, S. H. (2010). Locomotor imagery training improves gait performance in people with chronic hemiparetic stroke: a controlled clinical trial. Clin. Rehabil. 24, 514-522. doi: 10.1177/026921 5509360640

Ietswaart, M., Johnston, M., Dijkerman, H. C., Joice, S., Scott, C. L., MacWalter, R. S., et al. (2011). Mental practice with motor imagery in stroke recovery: randomized controlled trial of efficacy. Brain 134, 1373-1386. doi: 10.1093/brain/awr077

Johnson, S. H. (2000). Imagining the impossible: intact motor representations in hemiplegics. Neuroreport 11, 729-732. doi: 10.1097/ 00001756-200003200-00015

Keus, S. H., Bloem, B. R., van Hilten, J. J., Ashburn, A., and Munneke, M. (2007a). Effectiveness of physiotherapy in Parkinson's disease: the feasibility of a randomised controlled trial. Parkinsonism Relat. Disord. 13, 115-121. doi: 10.1016/j.parkreldis.2006.07.007

Keus, S. H., Bloem, B. R., Hendriks, E. J., Bredero-Cohen, A. B., and Munneke, M. (2007b). Evidencebased analysis of physical therapy in Parkinson's disease with recommendations for practice and research. Mov. Disord. 22, 451-460. doi: $10.1002 / \mathrm{mds} .21244$

Keus, S. H., Oude Nijhuis, L. B., Nijkrake, M. J., Bloem, B. R., and Munneke, M. (2012). Improving community healthcare for patients with Parkinson's disease: the dutch model. Parkinsons Dis. 2012:543426. doi: 10.1155/2012/543426

Kim, J. S., Oh, D. W., Kim, S. Y., and Choi, J. D. (2011). Visual and kinesthetic locomotor imagery training integrated with auditory step rhythm for walking performance of patients with chronic stroke. Clin. Rehabil. 25, 134-145. doi: 10.1177/0269215510380822

Langhorne, P., Coupar, F., and Pollock, A. (2009). Motor recovery after stroke: a systematic review. Lancet Neurol. 8, 741-754. doi 10.1016/S1474-4422(09)70150-4

Liu, K. P. (2009). Use of mental imagery to improve task generalisation after a stroke. Hong Kong Med. J. 15(3 Suppl. 4), 37-41.

Liu, K. P., Chan, C. C., Lee, T. M., and Hui-Chan, C. W. (2004). Mental imagery for promoting relearning for people after stroke: a randomized controlled trial. Arch. Phys. Med. Rehabil. 85, 1403-1408. doi: 10.1016/j.apmr.2003.12.035

Liu, K. P., Chan,C. C., Wong, R. S., Kwan, I. W., Yau, C. S., Li, L. S., et al. (2009). A randomized controlled trial of mental imagery augment generalization of learning in acute poststroke patients. Stroke 40, 2222-2225. doi: 10.1161/STROKEAHA.108 540997

Malouin, F., and Richards, C. L. (2010). Mental practice for relearning locomotor skills. Phys. Ther. 90, 240-251. doi: 10.2522/ptj.20090029

Malouin, F., Richards, C. L., Durand, A., and Doyon, J. (2008a). Reliability of mental chronometry for assessing motor imagery ability after stroke. Arch. Phys. Med. Rehabil. 89, 311-319. doi: 10.1016/j.apmr.2007.11.006

Malouin, F., Richards, C. L., Durand, A., and Doyon, J. (2008b). Clinical assessment of motor imagery after stroke. Neurorehabil. Neural Repair 22, 330-340. doi: 10.1177/1545968307313499

Malouin, F., Richards, C. L., Jackson, P. L., Lafleur, M. F., Durand, A., and Doyon, J. (2007). The Kinesthetic and Visual Imagery Questionnaire (KVIQ) for assessing motor imagery in persons with physical disabilities: a reliability and construct validity study. J. Neurol. Phys. Ther.
31, 20-29. doi: 10.1097/01.NPT. 0000260567.24122 .64

Martin, K. A., Moritz, S. E., and Hall, C. R. (1999). Imagery use in sport: a literature review and applied model. Sport Psychol. 13, 245-268.

Moseley, G. L., Zalucki, N., and Birklein, F. (2008). Thinking about movement hurts: the effect of motor imagery on pain and swelling in people with chronic arm pain. Arthritis Rheum. 50, 623-631. doi: 10.1002/art.23580

Mulder, T. (2007). Motor imagery and action observation: cognitive tools for rehabilitation. J. Neural Transm. 114, 1265-1278. doi: 10.1007/s00702-007-0763-Z

Muller, K., Butefisch, C. M., Seitz, R. J., and Homberg, V. (2007) Mental practice improves hand function after hemiparetic stroke. Restor. Neurol. Neurosci. 25, 501-511.

Munneke, M., Nijkrake, M. J., Keus, S. H., Kwakkel, G., Berendse, H. W., Roos, R. A., et al. (2010). Efficacy of community-based physiotherapy networks for patients with Parkinson's disease: a clusterrandomised trial. Lancet Neurol. 9, 46-54. doi: 10.1016/S1474-4422 (09)70327-8

Murphy, S. M., and Jowdy, D. P. (1992). Imagery and mental rehearsal. $A d v$. Sport Psychol. 221-250.

Newman, M., and Barker, K. (2012). The effect of supported standing in adults with upper motor neurone disorders: a systematic review. Clin. Rehabil. 26, 1059-1077. doi: $10.1177 / 0269215512443373$

Nilsen, D. M., Gillen, G., and Gordon, A. M. (2010). Use of mental practice to improve upper-limb recovery after stroke: a systematic review. Am. J. Occup. Ther. 64, 695-708. doi: 10.5014/ajot.2010.09034

Olivo, S. A., Macedo, L. G., Gadotti, I. C., Fuentes, J., Stanton, T., and Magee, D. J. (2008). Scales to assess the quality of randomized controlled trials: a systematic review. Phys. Ther. 88, 156-175. doi: 10.2522/ptj. 20070147

Page, S. (2000). Imagery improves upper extremity motor functions in chronic stroke patients with hemiplegia: a pilot study. Occup. Ther. J. Res. 20, 200-215.

Page, S. J., Levine, P., and Khoury, J. C. (2009). Modified constraintinduced therapy combined with mental practice: thinking through better motor outcomes. Stroke 40, 551-554. doi: 10.1161/STROKEAHA.108.528760 
Page, S. J., Levine, P., and Leonard, A. C. (2005). Effects of mental practice on affected limb use and function in chronic stroke. Arch. Phys. Med. Rehabil. 86, 399-402. doi: 10.1016/j.apmr.2004. 10.002

Page, S. J., Levine, P., and Leonard, A. (2007). Mental practice in chronic stroke: results of a randomized, placebo-controlled trial. Stroke 38, 1293-1297. doi: 10.1161/01.STR. 0000260205.67348.2b

Page, S. J., Levine, P., Sisto, S., and Johnston, M. V. (2001). A randomized efficacy and feasibility study of imagery in acute stroke. Clin. Rehabil. 15, 233-240. doi: 10.1191/026921501672063235

Riccio, I., Iolascon, G., Barillari, M. R., Gimigliano, R., and Gimigliano, F. (2010). Mental practice is effective in upper limb recovery after stroke: a randomized single-blind crossover study. Eur. J. Phys. Rehabil. Med. 46, 19-25.

Royal College of Physicians of London. (2008). National Clinicial Guideline for Stroke. 3rd Edn. Sudbury: The Lavenham Press Ltd.

Schuster, C., Butler, J., Andrews, B., Kischka, U., and Ettlin, T. (2012). Comparison of embedded and added motor imagery training in patients after stroke: results of a randomised controlled pilot trial. Trials 13, 11. doi: 10.1186/1745-6215-13-11

Simmons, L., Sharma, N., Baron, J. C., and Pomeroy, V. M. (2008). Motor imagery to enhance recovery after subcortical stroke: who might benefit, daily dose, and potential effects. Neurorehabil. Neural Repair 22, 458-467. doi: $10.1177 / 1545968308315597$
Struijs, J. N., van Genugten, M. L., Evers, S. M., Ament, A. J., Baan, C. A., and van den Bos, G. A. (2005). Modeling the future burden of stroke in The Netherlands: impact of aging, smoking, and hypertension. Stroke 36, 1648-1655. doi: $10.1161 / 01 . S T R .0000173221$. 37568.d2

Tamir, R., Dickstein, R., and Huberman, M. (2007). Integration of motor imagery and physical practice in group treatment applied to subjects with Parkinson's disease. Neurorehabil. Neural Repair 21, 68-75. doi: $10.1177 / 1545968306292608$

The Nordic Cochrane Centre TCC. (2011). Review Manager (RevMan). Version 5.1. [computer program]. Copenhagen: The Nordic Cochrane Centre, The Cochrane Collaboration 2011.

Thornton, A., and Lee, P. (2000). Publication bias in meta-analysis: its causes and consequences. J. Clin. Epidemiol. 53, 207-216. doi: 10.1016/S0895-4356 (99)00161-4

Trombly, C. A., and Wu, C. Y. (1999). Effect of rehabilitation tasks on organization of movement after stroke. Am. J. Occup. Ther. 53, 333-344. doi: 10.5014/ajot.53.4.333

van de Port, I. G., Wevers, L. E., Lindeman, E., and Kwakkel, G. (2012). Effects of circuit training as alternative to usual physiotherapy after stroke: randomised controlled trial. $B M J$ 344:e2672. doi: 10.1136/bmj.e2672

van Peppen, R. P., Hendriks, H. J., van Meeteren, N. L., Helders, P. J., and Kwakkel, G. (2007). The development of a clinical practice stroke guideline for physiotherapists in The Netherlands: a systematic review of available evidence. Disabil. Rehabil. 29, 767-783. doi: 10.1080/ 09638280600919764

Van Tulder, M., Furlan, A., Bombardier, C., and Bouter, L. M. (2003). Updated method guidelines for systematic reviews in the Cochrane collaboration back review group. Spine 28, 1290-1299. doi: 10.1097/ 01.BRS.0000065484.95996.AF

van Tulder, M. W., Ostelo, R., Vlaeyen, J. W., Linton, S. J., Morley, S. J., and Assendelft, W. J. (2001). Behavioral treatment for chronic low back pain: a systematic review within the framework of the cochrane back review group. Spine 26, 270-281. doi: 10.1097/00007632-20010201000012

Verhagen, A. P., de Vet, H. C., de Bie, R. A., Kessels, A. G., Boers, M. Bouter, L. M., et al. (1998). The Delphi list: a criteria list for quality assessment of randomized clinical trials for conducting systematic reviews developed by Delphi consensus. J. Clin. Epidemiol. 51, 1235-1241. doi: 10.1016/S08954356(98)00131-0

Verma, R., Arya, K. N., Garg, R. K., and Singh, T. (2011). Task-oriented circuit class training program with motor imagery for gait rehabilitation in poststroke patients: a randomized controlled trial. Top. Stroke Rehabil. 18(Suppl. 1), 620-632. doi: $10.1310 /$ tsr18s01-620

Welfringer, A., Leifert-Fiebach, G., Babinsky, R., and Brandt, T (2011). Visuomotor imagery as a new tool in the rehabilitation of neglect: a randomised controlled study of feasibility and efficacy. Disabil. Rehabil. 33, 2033-2043. doi 10.3109/09638288.2011.556208
WHO, (2013). The International Classification of Functioning, Disability and Health-ICF. Geneva: World Health Organisation. Available online at: http:// www.who.int/classifications/icf/en/ (Accessed May 2, 2013).

Zimmermann-Schlatter, A., Schuster, C., Puhan, M. A., Siekierka, E., Steurer, J. (2008). Efficacy of motor imagery in post-stroke rehabilitation: a systematic review. J. Neuroeng. Rehabil. 5, 8. doi: 10.1186/1743-0003-5-8

Conflict of Interest Statement: The authors declare that the research was conducted in the absence of any commercial or financial relationships that could be construed as a potential conflict of interest.

Received: 08 March 2013; accepted: 04 July 2013; published online: 02 August 2013.

Citation: Braun S, Kleynen M, van Heel T, Kruithof N, Wade D and Beurskens A (2013) The effects of mental practice in neurological rehabilitation; a systematic review and meta-analysis. Front. Hum. Neurosci. 7:390. doi: 10.3389/ fnhum.2013.00390

Copyright (c) 2013 Braun, Kleynen, van Heel, Kruithof, Wade and Beurskens. This is an open-access article distributed under the terms of the Creative Commons Attribution License (CC BY). The use, distribution or reproduction in other forums is permitted, provided the original author(s) or licensor are credited and that the original publication in this journal is cited, in accordance with accepted academic practice. No use, distribution or reproduction is permitted which does not comply with these terms. 


\section{APPENDIX}

Table A1 | Amsterdam-Maastricht Consensus List for quality assessment rating criteria.

Item Rating criteria

(1A) Randomization

Item has a positive score if the concealment of treatment allocation is explicitly described to be randomized (e.g., computer generated block randomization)

Note: Quasi-randomization is scored negative (e.g., randomization of dates of birth or day of the week)

(1B) Concealment of allocation

Item has a positive score if explicitly is described that the allocation of the intervention was blinded (e.g., a independent assessor performs the allocation and has no information/influence on who will be allocated to which group)

(2) Comparable sub groups at baseline

Item has a positive score if the study groups are comparable at baseline with the most important prognostic factors (e.g., comparable mean age and standard deviation in the study groups)

(3) Blinded care provider

Item has a positive score if the care provider is blinded regarding treatment allocation (e.g., the care provider is unaware of the content of the intervention*)

(4) Correction for attention; same treatment (dose), co-intervention

Item has a positive score if the different intervention groups have the same treatment dose and if co-interventions are equally divided among the intervention groups. Also, participants in both groups are asked to provide the same information (e.g., fill in logs) and undergo the same tests (battery)

(5) Acceptable compliance Item has a positive score if participants themselves or therapist and relatives report that the participants followed the given instructions (e.g., through logs, interviews)

(6) Blinded patient

Item has a positive score if patients are blinded regarding treatment allocation and if the method of blinding is appropriate (e.g., the patient is unaware of the treatment content*)

(7) Acceptable withdrawals during intervention period

Item has a positive score if the percentage of patients that drop out of the study does not exceed $10 \%$ during the intervention period. Another $10 \%$ of loss to follow-up of the remaining sample is set as acceptable for the follow-up period

(8) Blinded outcome assessor Item has a positive score if the outcome assessors are blinded regarding treatment allocation (e.g., independent raters, who are unaware of the treatment group that the participant is in-preferably checked by asking the rater to predict who is in which group)

(9) Relevance measures

Item has a positive score if the measurement instruments allow answering the research question

(10) Timing assessment Item has a positive score if the outcome assessment takes place approximately at the same time in all intervention groups. Also, a follow-up period of at least 3 months is set to be acceptable

(11) Intention to treat analysis

Item has a positive score if all randomized patients are reported for all measuring points and are analysed according to the group they were originally randomized to

*Blinding of the care provider and of the patient is not always applicable in physical therapy because of the nature of physical therapy interventions (e.g., manual therapy, exercises). Proper double blinding, therefore, is unlikely to be accomplished for most physical therapy trials (Olivo et al., 2008). 